\title{
Implications of lower-mantle structural heterogeneity for existence and nature of whole-mantle plumes
}

\author{
Edward J. Garnero \\ School of Earth and Space Exploration, Bateman Physical Sciences Building, \\ F-wing, Arizona State University, Tempe, Arizona 85287-1404, USA \\ Thorne Lay \\ Earth and Planetary Sciences Department, 1156 High Street, \\ University of California, Santa Cruz, California 95064, USA \\ Allen McNamara \\ School of Earth and Space Exploration, Bateman Physical Sciences Building, \\ F-wing, Arizona State University, Tempe, Arizona 85287-1404, USA
}

\begin{abstract}
Recent seismological studies demonstrate the presence of strong deep-mantle elastic heterogeneity and anisotropy, consistent with a dynamic environment having chemical anomalies, phase changes, and partially molten material. The implications for deep-mantle plume genesis are discussed in the light of the seismological findings. Nearly antipodal large low-shear velocity provinces (LLSVPs) in the lowermost mantle beneath the Pacific Ocean and Africa are circumscribed by high-velocity regions that tend to underlie upper-mantle downwellings. The LLSVPs have sharp boundaries, low $V_{\mathrm{S}} / V_{\mathrm{P}}$ ratios, and high densities; thus, they appear to be chemically distinct structures. Elevated temperature in LLSVPs may result in partial melting, possibly accounting for the presence of ultra-low-velocity zones detected at the base of some regions of LLSVPs. Patterns in deep-mantle fast shear wave polarization directions within the LLSVP beneath the Pacific are consistent with strong lateral gradients in the flow direction. The thermal boundary layer at the base of the mantle is a likely location for thermal instabilities that form plumes, but geodynamical studies show that the distribution of upwellings is affected when piles of dense chemical heterogeneities are present. The location of lowermost mantle plume upwellings is predicted to be near the boundaries of the large thermochemical complexes comprising LLSVPs. These observations suggest that any large mantle plumes rising from the deep mantle that reach the surface are likely to be preferentially generated in regions of distinct mantle chemistry, with nonuniform spatial distribution. This hypothesis plausibly accounts for some attributes of major hotspot volcanism.
\end{abstract}

Keywords: core-mantle boundary, D", plumes, thermochemical piles, hotspots

\footnotetext{
*E-mail: garnero@asu.edu.

Garnero, E.J., Lay, T., and McNamara, A., 2007, Implications of lower-mantle structural heterogeneity for existence and nature of whole-mantle plumes, in Foulger, G.R., and Jurdy, D.M., eds., Plates, plumes, and planetary processes: Geological Society of America Special Paper 430, p. 79-101, doi: 10.1130/2007.2430(05). For permission to copy, contact editing@geosociety.org. (02007 The Geological Society of America. All rights reserved.
} 


\section{INTRODUCTION}

The depth of origin of the source of long-lived hotspot volcanism has been of great interest to geological scientists for decades (e.g., Morgan, 1971). This question intersects nearly all Earth science disciplines, and hence continues to attract active debate. The most common interpretation is that thermal plumes rise from an internal mantle thermal boundary layer and sustain hotspot activity. As long as heat is flowing into the base of the mantle from the core-an apparent requirement for long-term maintenance of the geodynamo (e.g., Buffett, 2002) - a thermal boundary layer should be present at the base of the lower mantle. This boundary layer is commonly invoked as the source of deep mantle plumes (see Lay, 2005), consistent with the early notions advanced by Morgan. Certainly, cylindrical plumes commonly initiate from the basal boundary layers in numerical and experimental convection experiments with basal heating or basal injection of fluid (e.g., Davies, 1990; Olson and Kincaid, 1991; Farnetani and Richards, 1994; van Keken, 1997; Farnetani and Samuel, 2005; Lin and van Keken, 2005), carrying heat and any unique isotopic signatures from the boundary layer to the surface. However, demonstrating that such plumes rise $\sim 2900 \mathrm{~km}$ from the core-mantle boundary (CMB), traversing the Earth's entire mantle, has proven challenging. Many discussions of this problem invoke very simple notions of the lowermantle boundary layer, at odds with recent seismic findings. Our goal is to place the question of deep-mantle plume genesis in the context of current seismological and geodynamical ideas about lower-mantle structure and processes. We will avoid the issue of connecting specific hotspot observations to plumes or alternate explanations, as that is addressed in detail elsewhere in this volume (e.g., Sleep, this volume). Our focus is on the implications of seismically defined lower-mantle structures for the occurrence and characteristics of any plumes that do rise from the lowermost mantle.

A number of fields (e.g., seismology, geodynamics, and geochemistry) have presented arguments and some evidence for deep mantle plumes (e.g., Ji and Nataf, 1998; Lin and van Keken, 2005; Montelli et al., 2006; Wen, 2006), but the issue is still under debate, and an increasing number of studies find that some hotspots do not require origins in the lower mantle (e.g., Cserepes and Yuen, 2000; Foulger and Pearson, 2001; Foulger et al., 2001; Courtillot et al., 2003). In this article, we focus primarily on the elastic structure of the deep mantle derived by seismic methods and the dynamics of plume initiation, stability, fixity, and longevity in the presence of the large-scale chemical heterogeneity suggested by the seismic results, including the fact that hotspots are typically only found away from regions of subduction. Over the past several years, a variety of deep-mantle structural characteristics have emerged from high-resolution imaging with broadband seismic data. These structures include chemically distinct provinces beneath the Pacific Ocean and Africa, thin ultra-low-velocity zones (ULVZs) at the CMB, deep-mantle seismic wave anisotropy, and variable occurrence and topography of the $\mathrm{D}^{\prime \prime}$ seismic velocity discontinuity. This article considers these deep-mantle findings, exploring their implications for the possibility of lowermost mantle plume origination. Key seismological observations are summarized in the next section, followed by a section that considers the chemistry and dynamics of these features. This description provides a framework for considering the implications for any deep mantle plumes that may rise to the surface.

\section{LOWERMOST MANTLE SEISMIC VELOCITY STRUCTURE}

It has been known for decades that relatively high seismic velocities in the deep mantle tend to underlie past or present subduction zones, whereas lower-than-average wavespeeds are commonly found beneath the Pacific Ocean, the southern Atlantic Ocean, and Africa (e.g., Dziewonski, 1984; Hager et al., 1985). The distribution of lower-mantle velocities is quite consistent among recent tomographic $\mathrm{S}$-wave velocity $\left(V_{\mathrm{S}}\right)$ models, but there is less consistency among P-wave velocity $\left(V_{\mathrm{P}}\right)$ models (Fig. 1). The differences between large-scale lower-mantle $V_{\mathrm{S}}$ and $V_{\mathrm{P}}$ heterogeneity have led to the inference that the origin of the velocity perturbations is not solely thermal (e.g., Masters et al., 2000). Unfortunately, until the $V_{\mathrm{P}}$ maps are better resolved (as indicated either by agreement between results from different studies or by demonstration that a particular study has produced the most robust results), it is difficult to confidently separate chemical and thermal effects based on the patterns of heterogeneity at the present time.

It has recently been demonstrated that the expected primary lower-mantle mineral- $(\mathrm{Mg}, \mathrm{Fe}) \mathrm{SiO}_{3}$, magnesium silicate in perovskite structure $(\mathrm{Pv})$ - should undergo a phase transformation at pressure-temperature conditions within a few hundred kilometers above the CMB (Murakami et al., 2004; Oganov and Ono, 2004; Tsuchiya et al., 2004; Lay et al., 2005). Pv transforms into a post-perovskite structure ( $\mathrm{pPv})$ that is predicted to be accompanied by a $V_{\mathrm{S}}$ increase of several percent, but little change in $V_{\mathrm{P}}$. This difference in response could be one cause of decoupling of variations in $V_{\mathrm{S}}$ and $V_{\mathrm{P}}$ in the lowermost mantle. The $V_{\mathrm{S}} / V_{\mathrm{P}}$ ratio should be highest in high-shear velocity regions because the phase transition will occur at shallower depths in cool regions that have higher seismic velocities to begin with. One challenge in seeking this behavior is uncertainty in the reference level for measuring velocity anomalies; for example, the increase in temperature in the thermal boundary layer above the CMB will tend to lower seismic velocities, with more pronounced effects on S-wave velocity than for P-wave velocities. As seen in Figure 1, most seismic models tend to have means of zero at a given depth, which affects inferences about relative velocity behavior significantly.

The circum-Pacific band of high shear velocities apparent in Figure 1 is plausibly linked to occurrence of $\mathrm{pPv}$ in regions with relatively low temperatures below present-day and historic subduction zones. If this link is the case, the large low-shear ve- 


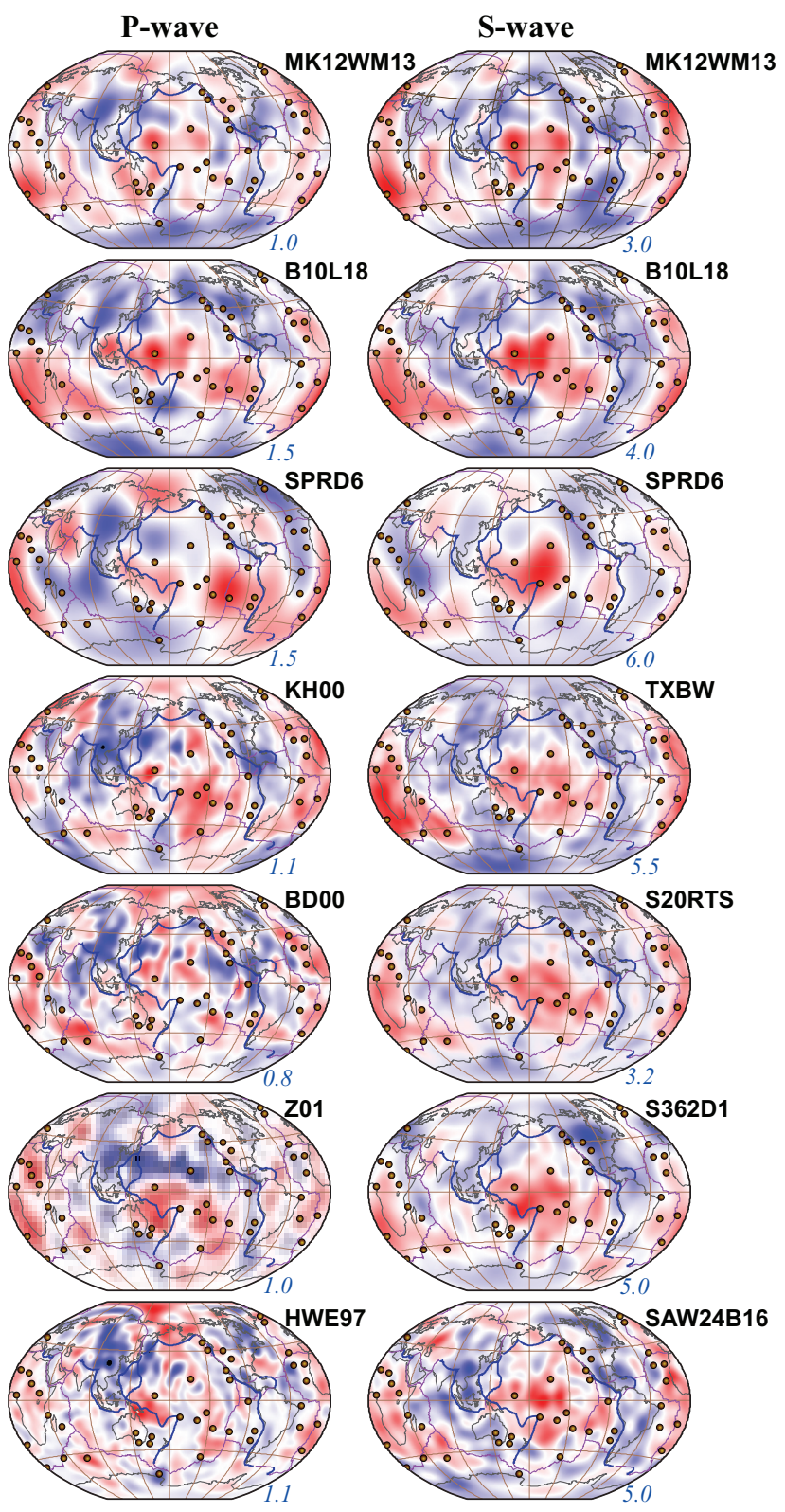

Figure 1. Tomographically derived P-wave (left column) and S-wave (right column) velocity perturbations at the base of the mantle. Red and blue colors indicate lower and higher velocities than global averages, respectively. Color scales are not uniform for the different models; the peak-to-peak value is indicated in the lower right of each map (blue number). Model names are given in the upper right and correspond to the following studies: MK12WM13 (Su and Dziewonski, 1997), B10L18 (Masters et al., 2000), SPRD6 (Ishii and Tromp, 2004), KH00 (Kárason and van der Hilst, 2001), TXBW (Grand, 2002), BD00 (Becker and Boschi, 2002), S20RTS (Ritsema and van Heijst, 2000), Z01 (Zhao, 2001), S362D1 (Gu et al., 2001), HWE97 (van der Hilst et al., 1997), and SAW24B16 (Mégnin and Romanowicz, 2000). More information comparing many of these models is found in Becker and Boschi (2002). Hotspot locations (from Steinberger, 2000) are shown as red-filled circles. Plate boundaries are magenta lines, but convergent boundaries are shown in blue. locity provinces (LLSVPs) beneath Africa and the Pacific might have no $\mathrm{pPv}$ or only a very thin layer of it, and may be relatively warm. The $\mathrm{Pv}-\mathrm{pPv}$ phase boundary has a large positive Clapeyron slope that would allow large lateral variations of thickness of a layer of $\mathrm{pPv}$ within the boundary layer to be caused by largescale thermal variations. The LLSVPs are basically isolated from locations where subduction has occurred over the past 200 m.y., which is commonly invoked as an indication of control on the deep seismic heterogeneity by large-scale mid-mantle convection coupled to the shallow subduction history. The relatively low shear velocities in LLSVPs can thus be attributed to a combination of relatively high temperature and lack of $\mathrm{pPv}$, but there are indications that there is also a chemical anomaly present in the LLSVPs.

Several free-oscillation studies have found evidence for lateral variation in large-scale lowermost-mantle density distribution (Ishii and Tromp, 1999, 2004; Kuo and Romanowicz, 2002; Trampert et al., 2004). Although debate continues on this topic (Romanowicz, 2001; Masters and Gubbins, 2003), indications are that a density increase is associated with the strongest $V_{\mathrm{S}}$ reductions located in LLSVPs (e.g., Ishii and Tromp, 1999; Trampert et al., 2004). Simultaneous analysis of $V_{\mathrm{S}}$ and $V_{\mathrm{P}}$ behavior further suggests that LLSVPs have bulk sound velocity anomalies (increases) that are anticorrelated with the low-shear velocity anomalies (e.g., Masters et al., 2000). These observations suggest that LLSVPs are chemically distinct from the surrounding mantle. This possibility immediately complicates the interpretation of these regions, because chemical differences can also affect the occurrence of the $\mathrm{pPv}$ phase change, and some compositional effects, such as iron enrichment, tend to reduce shear velocity as much or more than high temperature does at high pressures. The presence of iron or aluminum can also affect the phase transition pressure and sharpness (see Lay et al., 2005), although the magnitude of such effects is being debated. Sorting out these tradeoffs requires more detailed structural information than provided by tomography alone.

Portions of LLSVPs have been characterized at relatively short scale lengths (e.g., study regions spanning 500-1000 km laterally) using forward modeling of body wave travel times and waveforms. For example, a significant number of LLSVP margins (Fig. 2) show strong evidence for an abrupt lateral transition over a few hundred kilometers or less between the LLSVP and surrounding mantle. The sharpness of the LLSVP margins supports the notion that there is a chemical contribution because thermal gradients should be more gradual. Additionally, weak reflections from a velocity decrease in the upper portion of the LLSVP in the Pacific may indicate a chemical boundary (Lay et al., 2006) or a phase boundary within chemically distinct LLSVP material (Ohta et al., 2007). Additional internal layering within the LLSVP beneath the Pacific has been inferred from seismic wavefield reflectivity resolved by stacking a large number of seismic data (Lay et al., 2006). In Lay et al. (2006), the northern portion of the LLSVP beneath the Pacific Ocean is found to have a sharp velocity increase overlying a sharp decrease that 


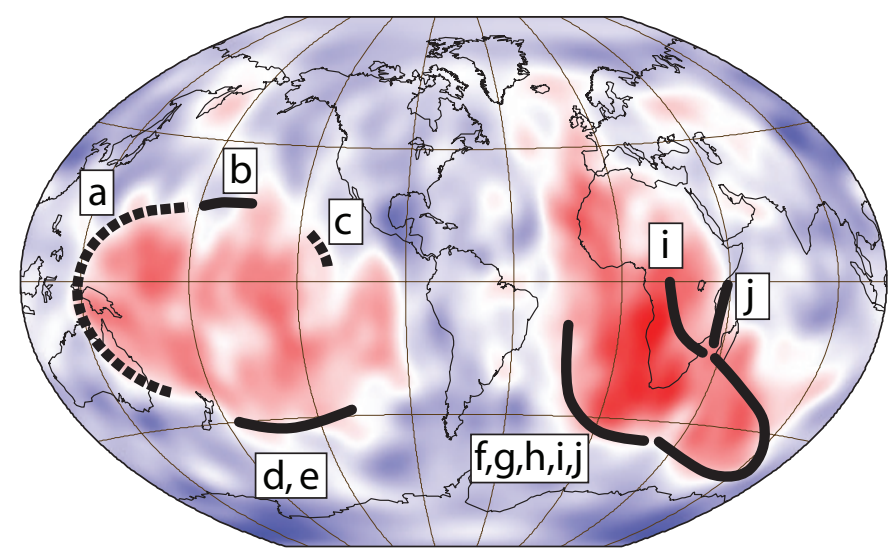

Figure 2. Map showing lowermost-mantle $V_{\mathrm{S}}$ perturbations from model TXBW (Grand, 2002; color scale is the same as in Fig. 1), along with locations where seismic studies have inferred distinct edges to the large low-shear velocity provinces (LLSVPs; thick black lines) using waveform and/or travel time analyses. Lower-cased letters in boxes indicate specific studies for different regions: a (He et al., 2006), b (Luo et al., 2001), c (Bréger and Romanowicz, 1998), d (To et al., 2005), e (Ford et al., 2006), f (Ni and Helmberger, 2001), g (Wen et al., 2001), h (Ni et al., 2002), i (Ni and Helmberger, 2003a,b), j (Wang and Wen, 2004). Solid lines indicate regions with sharp lateral boundaries, and dashed lines indicate regions where the LLSVP edges are only loosely resolved by travel time analysis.

was attributed to forward and reverse transformations of $\mathrm{Pv}$ to pPv (as predicted by Hernlund et al., 2005). This region is also underlain by a mild ULVZ (Avants et al., 2006). Lateral depth variations of the mapped perovskite phase boundaries within the LLSVP are consistent with a lateral increase in temperature toward the LLSVP margin in the central Pacific region.

In addition to evidence for sharp boundaries of the two LLSVPs, several forward modeling studies have advocated a chemical origin for isolated seismic heterogeneities at small to intermediate scales (500-1000 km; e.g., Wysession et al., 1994; Bréger and Romanowicz, 1998), as well as at small scales (one to tens of kilometers) that scatter seismic waves and contribute to high-frequency coda energy (e.g., Hedlin and Shearer, 2000; Earle and Shearer, 2001). Some of the small-scale scattering features at the CMB have been attributed to partial melt of deepmantle material (e.g., Vidale and Hedlin, 1998; Wen and Helmberger, 1998, Rost et al., 2005), owing primarily to magnitude of the requisite velocity reductions and a $3: 1 V_{\mathrm{S}}: V_{\mathrm{P}}$ velocity reduction ratio. It is difficult to attribute large deep-mantle velocity reductions (e.g., $>10 \%$ ) to any expected deep-mantle materials in the absence of some level of melt; in fact, the possibility of partial melt in the deep mantle has been advocated as an explanation for the occurrence of thin ULVZs right above the CMB (Williams and Garnero, 1996; Revenaugh and Meyer, 1997). ULVZs appear to exist preferentially beneath low- $V_{\mathrm{S}}$ regions, including the two LLSVPs (e.g., Garnero et al., 1998; Williams et al., 1998). This preference is hard to quantify because the global distribution of ULVZ structure is not presently well constrained; less than half of the surface area of the CMB has been even qualitatively characterized (Thorne and Garnero, 2004). However, the CMB in some isolated spots has been analyzed in great detail, suggesting partial melt in small domes, small dense zones with a flat top, and even small pockets right beneath the CMB with anomalous properties (Wen and Helmberger, 1998; Helmberger et al., 1998, 2000; Wen, 2000; Rost and Revenaugh, 2001; Rost et al., 2005). These structures all point to complex processes occurring down to small scales, undoubtedly related to high temperatures at the base of the mantle thermal boundary layer.

Lowermost-mantle seismic wave anisotropy may also offer clues to deep-mantle chemistry and dynamics; as suggested by seismic studies (e.g., see Kendall and Silver, 1998; Lay et al., 1998; Kendall, 2000), mineral physics calculations (e.g., Stixrude, 1998; Karki et al., 1999; Mainprice et al., 2000; Wentzcovitch et al., 2004; Hirose, 2006; Hirose et al., 2006), as well as by geodynamics experiments (e.g., McNamara et al., 2001, 2002, 2003). Several seismological studies have mapped geographical changes in the fast propagation direction of deepmantle shear waves (Russell et al., 1998; Garnero et al., 2004; Wookey et al., 2005; Rokosky et al., 2006). In one case, geometrical patterns in fast propagation directions have been interpreted as being related to lowermost-mantle boundary layer convective currents that may involve flow into a boundary layer upwelling, possibly related to a plume that rises to the Hawaiian hotspot (Russell et al., 1998). Given that there is a firstorder correlation between the distribution of surface hotspots and the locations of the LLSVPs (e.g., Thorne et al., 2004; any correlation is less apparent for P-wave velocity heterogeneity) at the base of the mantle (Fig. 1), it is reasonable to seek any evidence for plumes extending through the mantle above these regions.

Direct seismic imaging of any deep mantle plumes is very difficult, primarily owing to the expected small dimension of the plume conduit (e.g., $<500 \mathrm{~km}$ ) compared to the long seismic wave propagation paths (typically $>5000 \mathrm{~km}$; see, e.g., Nataf, 2000; Dahlen, 2004). Most tomographic efforts have not directly imaged vertically continuous deep mantle plumes or their relationship to LLSVPs, as the minimum lateral wavelength of resolvability is commonly $>1000 \mathrm{~km}$. One notable exception is the study by Montelli et al. (2004), in which several surface hotspots are inferred to be underlain by low $V_{\mathrm{P}}$ values extending down to the CMB (this observation is currently under active debate; see Dahlen and Nolet, (2005); de Hoop and van der Hilst, 2005). The seismological community may eventually converge on models that either support or refute the existence of wholemantle low-velocity plume conduits. However, deep-mantle seismic plume detection may be almost impossible if plume temperature does not significantly exceed the surrounding mantle (e.g., Farnetani, 1997; Farnetani and Samuel, 2005), giving too small an elastic velocity signature. If the velocity perturbations are, in fact, strong enough, there is some hope to image plume features if wavepath coverage is dense enough (e.g., 
Tilmann et al., 1998), but at present, this imaging does not appear to have been done convincingly.

Less direct approaches, such as correlation studies of surface hotspot distributions and deep-mantle velocity patterns have been pursued over several decades (e.g., Morgan, 1971; Hager et al., 1985; Thorne et al., 2004), but such analyses do not unequivocally constrain or require the existence of whole-mantle plumes.

\section{LOWER-MANTLE CHEMISTRY AND DYNAMICS}

Several conceptual models have been developed in recent years to explain the observed LLSVPs. It proves dynamically difficult to account for the huge low-velocity anomalies beneath Africa and the Pacific in an isochemical mantle, even in models that impose a large-scale pattern of downwelling by employing geologically recent plate velocities as surface boundary conditions (e.g., Bunge et al., 1998; McNamara and Zhong, 2005). In dynamical models that lack a thermochemical component, plumes tend to organize into clustered networks of thin upwellings (plume clusters) that form away from downwelling regions (e.g., Schubert et al., 2004; McNamara and Zhong, 2005). Although current research is assessing whether regions of plume clusters may resemble the large, low-velocity anomalies in the lowermost mantle when viewed through the blurred "eyes" of seismic tomography (Ritsema et al., 2007), it appears that thermochemical models of mantle convection provide the best explanation for the existence of the LLSVPs.

Thermochemical conceptual models that strive to explain the dynamics related to LLSVPs beneath Africa and the Pacific typically fall into two categories. Both invoke a large volume of anomalously dense mantle material; however, they differ in terms of the relative buoyancy and geologic longevity of the chemical anomaly.

The superplume hypothesis typically describes the large, low-velocity anomalies as being due to the presence of large, upward-doming plumes of the more-dense material (e.g., Davaille, 1999; Forte and Mitrovica, 2001; Davaille et al., 2002, 2005). These models are characterized by the denser component having a net positive buoyancy (the thermal buoyancy exceeds the negative buoyancy associated with the intrinsic density anomaly) such that it becomes unstable and forms large superplumes that are currently rising in the mantle. It has been shown (e.g., Davaille et al., 2002) that these structures may rise and sink many times before ultimately being well mixed into the background mantle. Smaller-scale thermal plumes can originate from the tops of these large domes, entraining some of the chemically distinct material in the dense dome. This entrainment may, in turn, explain the anomalous chemistry observed at ocean island basalts (OIBs; e.g., Hofmann, 1997, Fitton, this volume). One aspect of this model is that the present instance in Earth's history has the more-dense material actively rising, as opposed to other times in the past in which this material was either a stratified layer or sinking after a previous ascent.
Another, similar superplume phenomenon observed in geodynamical modeling involves the presence of long-lived, stable superplumes (McNamara and Zhong, 2004a). If the anomalously dense mantle component has a higher intrinsic viscosity $(\sim 100 \times)$ than the less-dense material, it may form large dome structures that migrate laterally across the lower mantle. These structures can maintain a vertical height, and they do not experience the rising and sinking observed in laboratory studies (e.g., Davaille et al., 2002). However, it is difficult to put forth a mineral physics explanation that would provide the necessary intrinsic viscosity increase to the dense material, so such a model is not favored here.

Although the basic superplume model remains a viable hypothesis, here we focus on the second category of thermochemical mantle hypotheses, which involve the presence of longlived, stable, dense piles of chemically distinct material (e.g., Christensen and Hofmann, 1994; Tackley 1998, 2002; Kellogg et al., 1999; Jellinek and Manga, 2002, 2004; Ni et al., 2002; McNamara and Zhong, 2004a,b, 2005; Nakagawa and Tackley, 2005; Tan and Gurnis, 2005). In these models, piles of dense material maintain a near-neutral (slightly negative) buoyancy, and as a result, they are passively swept aside by downwelling flow and are focused beneath upwelling regions. Piles tend to form large, ridge-like structures that have thermal plumes originating from their peaks that entrain a small fraction of the more-dense material.

McNamara and Zhong (2005) performed numerical thermochemical calculations in a 3-D spherical geometry with Earth's recent plate history imposed as surface boundary conditions (120 m.y. over eleven stages of plate motions, as provided by Lithgow-Bertelloni and Richards 1998). The calculation employed the Boussinesq approximation with constant thermodynamic properties; however, depth-dependent thermal conductivity was explored and found to have only a minimal effect on the resulting thermal and chemical structures. A depth- and temperature-dependent rheology that included a thirty-fold increase across the transition zone was used. The initial condition included a flat, 255-km-thick more-dense layer and a steadystate temperature field derived from an axisymmetric thermochemical calculation. The imposed plate history acted to guide the formation of downwellings in historical subduction regions, which resulted in the focusing of the lower-mantle dense material into piles beneath Africa and the Pacific. These are the same regions characterized by the observed LLSVPs (see Fig. 3A and D). This modeling demonstrated that it is dynamically feasible that global flow patterns derived from the history of subduction can focus a dense component into thermochemical structures that, to first order, resemble the present-day LLSVP configuration.

Our preferred interpretation of LLSVPs is that they are large, dense thermochemical piles stabilized by upwelling currents that are downwelling-induced return flow. The temperature within and around the pile depends on several uncertain factors, like thermal conductivity and the degree of viscous heat- 
ing. If we assume that deep-mantle piles have some temporal stability, then it is reasonable to assume they are denser than surrounding mantle (e.g., at a minimum, 2-5\% denser). This assumption is consistent with the suggestion from some seismic studies of increased density in these locations (Ishii and Tromp, 2004; Trampert et al., 2004). The possibility of Fe-enrichment in $\mathrm{D}^{\prime \prime}$ would decrease shear velocity and result in density elevation, so the chemical heterogeneity could be residual material from the core-formation process or accumulation of core-mantle reaction products. Subducted mid-ocean ridge basalt (MORB)

(A) Compositionally distinct, dense piles

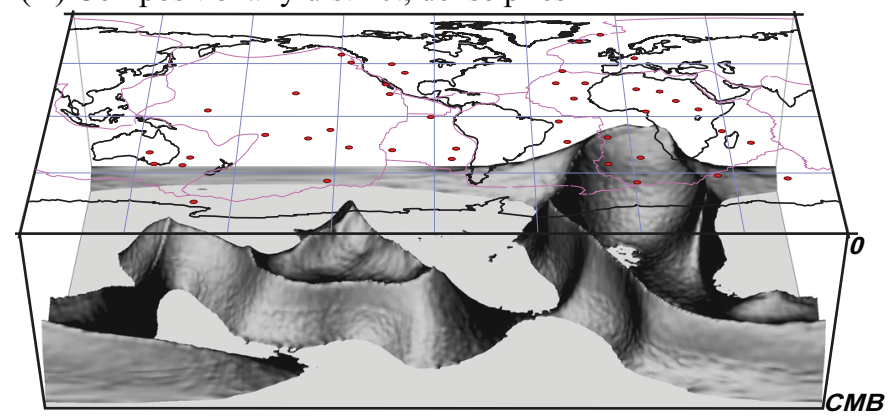

(B) Highest temperatures

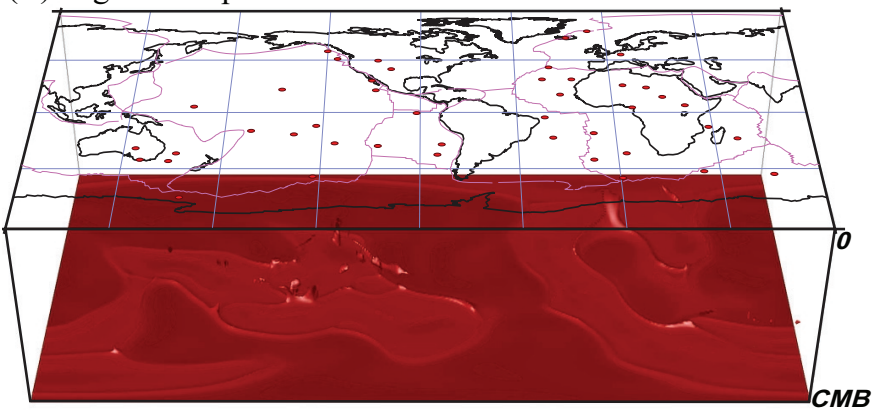

(C) Dense piles and temperatures

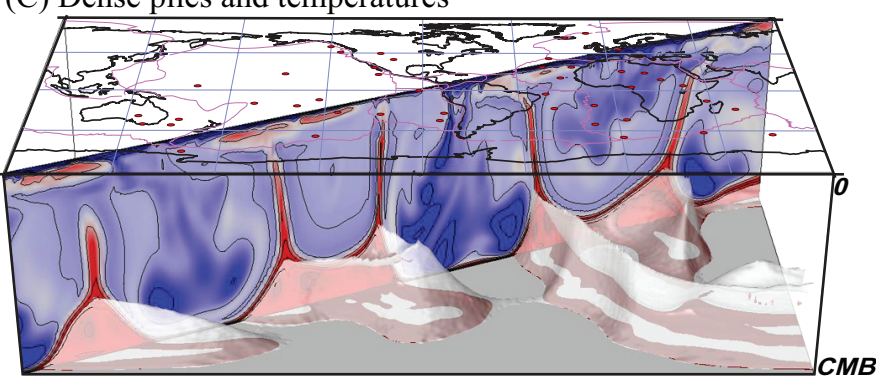

(D) Shear velocity heterogeneity

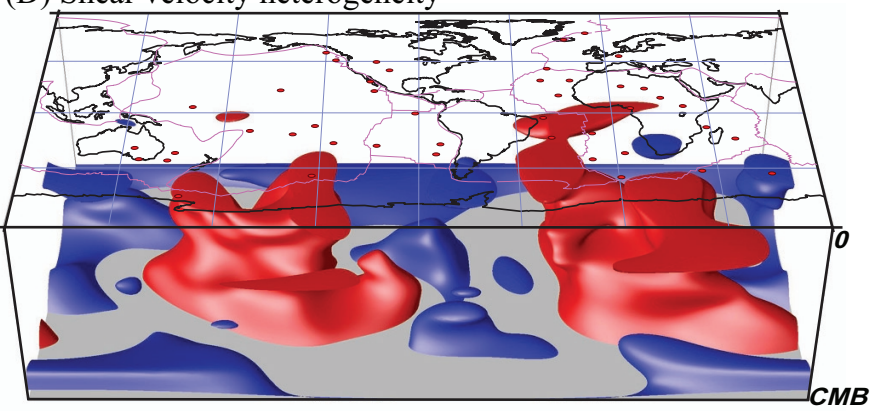

is also expected to be denser than surrounding material at lowermantle conditions and thus may account for the dense LLSVPs, assuming that MORB has accumulated progressively in the lowermost mantle (Hirose et al., 1999; Ohta et al., 2007)

The detailed structure (e.g., topography) of the sides and top of chemically distinct LLSVP material can play a significant role in the style and morphology of local upwelling currents and plume initiation (e.g., Jellinek and Manga, 2002, 2004; McNamara and Zhong, 2005). Numerical calculations show upward convective return flow guided by the LLSVP margins. Basal heating and internal flow of the LLSVP cause the boundaries between the surrounding mantle and LLSVP to be particularly hot (see Fig. 3B). If partial melt is indeed the origin of ULVZ structure, we would expect the edges of LLSVP structure to have the highest occurrence of ULVZ structure. As previously mentioned, the geographical distribution of ULVZ structure at present is not known in great enough detail to document such a spatial correlation. It is noteworthy, however, that two recent high-resolution studies detailing ULVZ structure are both near (and within) LLSVP margins: a double-array stacking study of $\mathrm{ScS}$ (a core-reflected S-wave) beneath the northern margin of the LLSVP beneath the Pacific Ocean (Avants et al., 2006; Lay et al., 2006), and a multiple vespagram analysis of ScP (an Swave that converts to a $\mathrm{P}$-wave upon reflection at the $\mathrm{CMB}$ ) beneath the southwest margin of the same LLSVP (Rost et al., $2005,2006)$. The strongest lateral gradients in tomographically derived $V_{\mathrm{S}}$ structures are near the margins of the LLSVPs (consistent with pile "edges"), and these regions of strong gradients are found to statistically correlate with surface hotspot locations (Thorne et al., 2004).

These findings are consistent with the conceptual model put forth in Figures 3C and 4. Large thermochemical piles are deflected away from downwellings by subduction currents and are swept to concentrate beneath upwelling return flow. LLSVP piles may thus be the key to the long-term history of subduction. LLSVP topographical features near their margins guide upwelling and serve as sites of thermal boundary layer instabili-

Figure 3. Continents, plate boundaries, and hotspots are shown on maps at the top of four boxes that represent the area of the whole globe, and the volume of the mantle from the surface to the core-mantle boundary (CMB). (A) Compositionally distinct, dense piles from the geodynamic calculation of McNamara and Zhong (2005). (B) The locations of the hottest temperatures in the mantle for the calculation of panel A are shown. Isotemperature contour is 0.98 for the calculation that spans temperatures from 0 to 1 . The hottest temperatures are within the piles and are typically near the edges. (C) A temperature cross-section is shown, along with the piles from panel A in a transparent gray, and the hottest CMB temperatures of panel B are included (faint red stripes within the piles). Pile topography guides plume upwellings. (D) Shear velocity heterogeneity from Ritsema and van Heijst (2000) filtered to maximum spherical harmonic degree $1=8$, with iso-velocity contours at $-0.3 \%$ (red) and $0.5 \%$ (blue). Dense piles in the geodynamic calculation of panel A are geographically distributed similarly to the low velocities (red) in panel D. 

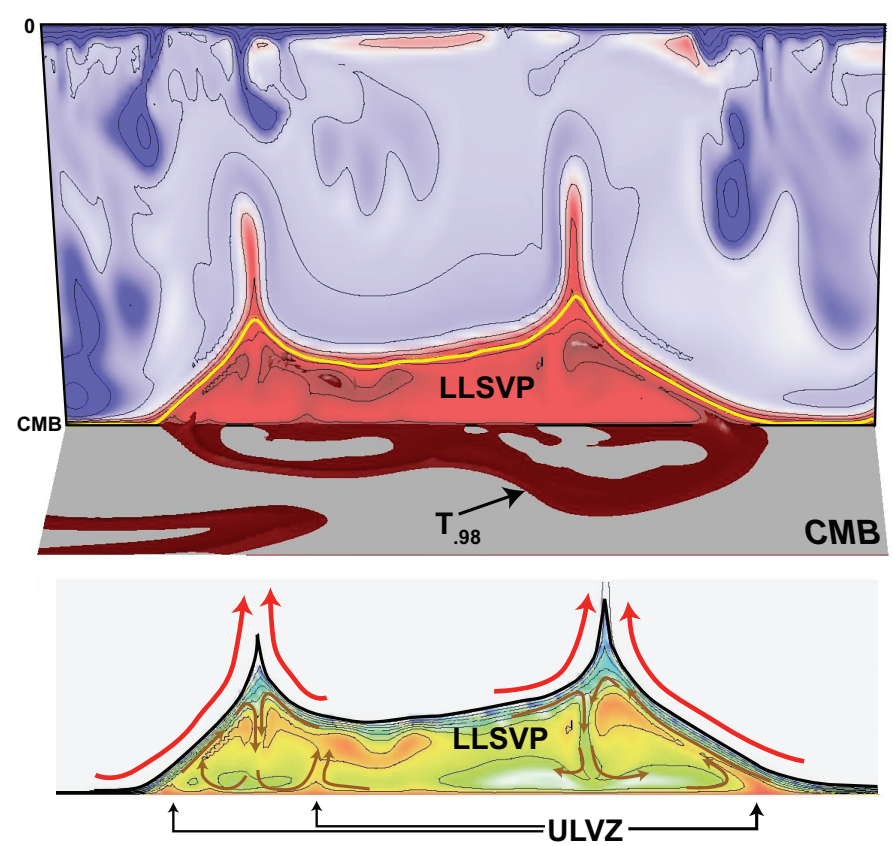

Figure 4. A close-up of the thermochemically dense pile beneath the Pacific Ocean in Figure 3A. (A) A cross-section from the surface to the core-mantle boundary $(\mathrm{CMB})$ displays temperature variations, with the yellow line denoting the boundary of the chemically distinct material in the pile. We identify the thermochemical anomaly as the large low-shear velocity province (LLSVP). Part of the CMB surface is shown in front of the cross-section, along with an isotemperature contour (at 0.98, as in Fig. 3). (B) The same cross-section, but only the pile, with a more expanded color scale (colors span $T=0.7$ to 1.0). Convective motions are indicated by the arrows. The hottest zones may invoke partial melt of LLSVP material, either at the CMB (denoted as an ultra-low velocity zone [ULVZ] in the figure), or in some isolated locations farther up within the LLSVP.

ties. Ascending plumes from the LLSVP margins may carry distinct chemical tracers from the deep mantle and CMB. OIB geochemistry for major hotspots favors recycled slab material as a significant source (e.g., Hofmann, 1997), which is consistent with past and/or ongoing subduction of slabs to the base of mantle and concentration of slab materials into the piles (e.g., Christensen and Yuen, 1984; Hager et al., 1985; Hutko et al., 2006). Thus, LLSVPs can be viewed as a by-product of whole-mantle convection, with physical segregation of dense material in the boundary layer. This process could occur today even if slabs temporarily go stagnant in the transition zone because of the difficulty of penetrating the $670-\mathrm{km}$ phase boundary (Mitrovica and Forte, 1997) before they avalanche into the lower mantle. Of course, not all slab material has to penetrate into the deep mantle, and the LLSVPs may be comprised of slab material subducted long ago.

Seismological evidence for reflections down to $1000 \mathrm{~km}$ beneath southwest Pacific subduction zones is consistent with the penetration of MORB-bearing material into the lower mantle (Rost et al., 2007). Sequestration of dense MORB material (e.g., Hirose et al., 1999; Tan and Gurnis, 2005; Ohta et al., 2007) may account for the chemically distinct nature of the LLSVP material. This concept certainly requires geochemical assessment, as it is the only approach to establishing the temporal isolation of the LLSVP reservoir.

\section{CONCLUSIONS}

Recent deep-mantle seismological findings give rise to the hypothesis that any deep mantle plumes will originate near the margins of LLSVPs at the base of the mantle. Chemically distinct and dense LLSVP piles may be organized underneath large-scale upwellings associated with return flow from subduction-induced downwellings. The margins of the LLSVP at the $\mathrm{CMB}$ are the hottest locations in the mantle and may contain partial melt at the CMB that is imaged as ULVZ structure. The LLSVP and ULVZ structures may contain important isotopic signatures that become entrained in plumes that rise from boundary layer instabilities on the LLSVP margins. The recent data and models do not demonstrate that whole-mantle plumes exist. However, the emerging understanding of lower-mantle structure and processes does provide guidance as to where and why any plume rising from the deep mantle will originate, and how they may sample thermally and chemically distinct source regions other than right at the $\mathrm{CMB}$.

\section{ACKNOWLEDGMENTS}

This work was supported in part by the U.S. National Science Foundation under grants EAR-0125595, EAR-0453884, EAR0453944, EAR-0510383, and EAR-0456356. Editors Gillian Foulger and Donna Jurdy and reviewers Anne Hofmeister and Dion Heinz made numerous helpful suggestions that improved the article. The authors thank Thorsten Becker for posting the tomography models from Becker and Boschi (2002) on his Web page and for software to expand the spherical harmonics, and Jeroen Ritsema for plotting software. Figures 1-3 were made with the aid of Generic Mapping Tools (Wessel and Smith, 1998).

\section{REFERENCES CITED}

Avants, M., Lay, T., and Garnero, E.J., 2006, A new probe of ULVZ S-wave velocity structure: Array stacking of ScS waveforms: Geophysical Research Letters, v. 33, p. L07314, doi: 10.1029/2005GL024989.

Becker, T.W., and Boschi, L., 2002, A comparison of tomographic and geodynamic mantle models: Geochemistry, Geophysics, and Geosystems, v. 3, doi: $2001 \mathrm{GC} 000168$.

Bréger, L., and Romanowicz, B., 1998, Thermal and chemical 3D heterogeneity in $\mathrm{D}^{\prime \prime}$ : Science, v. 282, p. 718-720, doi: 10.1126/science.282.5389.718.

Buffett, B.A., 2002, Estimates of heat flux in the deep mantle based on the power requirements for the geodynamo: Geophysical Research Letters, v. 29, doi: 10.1029/2001GL014649.

Bunge, H.-P., Richards, M.A., Lithgow-Bertelloni, C., Baumgardner, J.R., Grand, S.P., and Romanowicz, B.A., 1998, Time scales and heterogeneous structure in geodynamic Earth models: Science, v. 280, p. 91-95. 
Christensen, U.R., and Hofmann, A.W., 1994, Segregation of subducted oceanic crust in the convecting mantle: Journal of Geophysical Research, v. 99, p. 19,867-19,884, doi: 10.1029/93JB03403.

Christensen, U.R., and Yuen, D.A., 1984, The interaction of a subducting lithospheric slab with a chemical or phase boundary: Journal of Geophysical Research, v. 89, p. 4389-4402.

Courtillot, V., Davaille, A., Baesse, J., and Stock, J., 2003, Three distinct types of hotspots in the Earth's mantle: Earth and Planetary Science Letters, v. 205, p. 295-308, doi: 10.1016/S0012-821X(02)01048-8.

Cserepes, L., and Yuen, D.A., 2000, On the possibility of a second kind of mantle plume: Earth and Planetary Science Letters, v. 183, p. 61-71, doi: 10.1016/S0012-821X(00)00265-X

Dahlen, F.A., 2004, Resolution limit of traveltime tomography: Geophysical Journal International, v. 157, p. 315-331, doi: 10.1111/j.1365-246X.2004 .02214.x.

Dahlen, F.A., and Nolet, G., 2005, Comment on "On sensitivity kernels for wave equation transmission tomography": Geophysical Journal International, v. 163 , p. $949-951$.

Davaille, A., 1999, Simultaneous generation of hotspots and superswells by convection in a heterogeneous planetary mantle: Nature, v. 402, p. 756-760, doi: $10.1038 / 45461$.

Davaille, A., Girard, F., and Le Bars, M., 2002, How to anchor hotspots in a convecting mantle?: Earth and Planetary Science Letters, v. 203, p. 621-634, doi: 10.1016/S0012-821X(02)00897-X.

Davaille, A., Stutzmann, E., Silveira, G., Besse, J., and Courtillot, V., 2005, Convective patterns under the Indo-Atlantic box: Earth and Planetary Science Letters, v. 239, p. 233-252, doi: 10.1016/j.eps1.2005.07.024.

Davies, G.F., 1990, Mantle plumes, mantle stirring, and hotspot chemistry: Earth and Planetary Science Letters, v. 99, p. 94-109, doi: 10.1016/0012821X(90)90073-7.

de Hoop, M.V., and van der Hilst, R.D., 2005, Reply to comment by F.A. Dahlen and G. Nolet: Geophysical Journal International, v. 163, p. 952-955.

Dziewonski, A.M., 1984, Mapping the lower mantle-Determination of lateral heterogeneity in P-velocity up to degree and order 6: Journal of Geophysical Research, v. 89, p. 5929-5942.

Earle, P.S., and Shearer, P.M., 2001, Distribution of fine-scale mantle heterogeneity from observations of Pdiff coda: Bulletin of the Seismological Society of America, v. 91, p. 1875-1881, doi: 10.1785/0120000285.

Farnetani, C.G., 1997, Excess temperature of mantle plumes: The role of chemical stratification across D": Geophysical Research Letters, v. 24, p. 15831586, doi: 10.1029/97GL01548.

Farnetani, C.G., and Richards, M.A., 1994, Numerical investigations of the mantle plume initiation model for flood basalt events: Journal of Geophysical Research, v. 99, p. 13,813-13,833, doi: 10.1029/94JB00649.

Farnetani, C.G., and Samuel, H., 2005, Beyond the thermal plume paradigm: Geophysical Research Letters, v. 32, p. L07311, doi: 1029/2005GL022360.

Fitton, J.G., 2007 (this volume), The OIB paradox, in Foulger, G.R., and Jurdy, D.M., eds., Plates, plumes, and planetary processes: Boulder, Colorado, Geological Society of America Special Paper 430, doi: 10.1130/2007.2430(20).

Ford, S.R., Garnero, E.J., and McNamara, A.K., 2006, A strong lateral shear velocity gradient and anisotropy heterogeneity in the lowermost mantle beneath the southern Pacific: Journal of Geophysical Research, v. 111, p. B03306, doi: 10.1029/2004JB003574.

Forte, A.M., and Mitrovica, J.X., 2001, Deep-mantle high viscosity flow and thermochemical structure inferred from seismic and geodynamic data: Nature, v. 410, p. 1049-1056, doi: 10.1038/35074000.

Foulger, G.R., and Pearson, D.G., 2001, Is Iceland underlain by a plume in the lower mantle? Seismology and helium isotopes: Geophysical Journal International, v. 145, p. F1-F5, doi: 10.1046/j.0956-540x.2001.01457.x.

Foulger, G.R., Pritchard, M.J., Julian, B.R., Evans, J.R., Allen, R.M., Nolet, G., Morgan, W.J., Bergsson, B.H., Rlendsson, P., Jakobsdottir, S., Ragnarsson, S., Stefansson, R., and Vogfjörd, K., 2001, Seismic tomography shows that upwelling beneath Iceland is confined to the upper mantle: Geophysical Journal International, v. 146, p. 504-530, doi: 10.1046/j.0956-540x.2001 $.01470 . x$.
Garnero, E.J., Revenaugh, J., Williams, Q., Lay, T., and Kellogg, L.H., 1998 , Ultralow velocity zone at the core-mantle boundary, in Gurnis, M., et al., eds., The core-mantle boundary region: Washington D.C., American Geophysical Union, p. 319-334.

Garnero, E.J., Maupin, V., Lay, T., and Fouch, M.J., 2004, Variable azimuthal anisotropy in Earth's lowermost mantle: Science, v. 306, p. 259-261, doi: 10.1126/science. 1103411 .

Grand, S.P., 2002, Mantle shear-wave tomography and the fate of subducted slabs: Philosophical Transactions of the Royal Society of London A, v. 360, p. 2475-2491.

Gu, Y.J., Dziewonski, A.M., Su, W.J., and Ekström, G., 2001, Models of the mantle shear velocity and discontinuities in the pattern of lateral heterogeneities: Journal of Geophysical Research, v. 106, p. 11,169-11,199, doi: 10.1029/2001JB000340.

Hager, B.H., Clayton, R.W., Richards, M.A., Comer, R.P., and Dziewonski, A.M., 1985, Lower mantle heterogeneity, dynamic topography and the geoid: Nature, v. 313, p. 541-546, doi: 10.1038/313541a0.

He, Y., Wen, L., and Zheng, T., 2006, Geographic boundary and shear wave velocity structure of the "Pacific anomaly" near the core-mantle boundary beneath western Pacific: Earth and Planetary Science Letters, v. 244, p. 302-314, doi: 10.1016/j.eps1.2006.02.007.

Hedlin, M.A.H., and Shearer, P.M., 2000, An analysis of large-scale variations in small-scale mantle heterogeneity using Global Seismic Network recordings of precursors to PKP: Journal of Geophysical Research, v. 105, p. 13,655-13,673, doi: 10.1029/2000JB900019.

Helmberger, D.V., Wen, L., and Ding, X., 1998, Seismic evidence that the source of the Iceland hotspot lies at the core-mantle boundary: Nature, v. 396, p. 251-255, doi: 10.1038/24357.

Helmberger, D.V., Ni, S., Wen, L., and Ritsema, J., 2000, Seismic evidence for ultra low velocity zones beneath Africa and the Atlantic Ocean: Journal of Geophysical Research, v. 105 , p. 23,865-23,878, doi: 10.1029/2000 JB900143.

Hernlund, J.W., Thomas, C., and Tackley, P.J., 2005, A doubling of the postperovskite phase boundary and the structure of the lowermost mantle: Nature, v. 434, p. 882-886, doi: 10.1038/nature03472.

Hirose, K., 2006, Postperovskite phase transition and its geophysical implications: Reviews of Geophysics, v. 44, p. RG3001, doi: 10.1029/2005 RG000186.

Hirose, K., Fei, Y., Ma, Y., and Mao, H.-K., 1999, The fate of subducted basaltic crust in the Earth's lower mantle: Nature, v. 397, p. 53-56, doi: 10.1038/ 16225 .

Hirose, K., Karato, S.-I., Cormier, V.F., Brodholt, J.P., and Yuen, D.A., 2006, Unsolved problems in the lowermost mantle: Geophysical Research Letters, v. 33, p. L12S01, doi:10.1029/2006GL025691.

Hofmann, A.W., 1997, Mantle geochemistry: The message from oceanic volcanism: Nature, v. 385, p. 219-229, doi: 10.1038/385219a0.

Hutko, A., Lay, T., Garnero, E.J., and Revenaugh, J.S., 2006, Seismic detection of folded, subducted lithosphere at the core-mantle boundary: Nature, v. 441, p. 333-336, doi: 10.1038/nature04757.

Ishii, M., and Tromp, J., 1999, Normal-mode and free-air gravity constraints on lateral variations in velocity and density of Earth's mantle: Science, v. 285 , p. 1231-1236, doi: 10.1126/science.285.5431.1231.

Ishii, M., and Tromp, J., 2004, Constraining large-scale mantle heterogeneity using mantle and inner-core sensitive normal modes: Physics of the Earth and Planetary Interiors, v. 146, p. 113-124, doi: 10.1016/j.pepi.2003 .06 .012 .

Jellinek, A.M., and Manga, M., 2002, The influence of a chemical boundary layer on the fixity, spacing, and lifetime of mantle plumes: Nature, v. 418, p. 760-763, doi: 10.1038/nature00979.

Jellinek, A.M., and Manga, M., 2004, Links between long-lived hot spots, mantle plumes, D", and plate tectonics: Reviews of Geophysics, v. 42, doi: 10.1029/2003RG000144.

Ji, Y., and Nataf, H.-C., 1998, Detection of mantle plumes in the lower mantle by diffraction tomography: Hawaii: Earth and Planetary Science Letters, v. 159 , p. $99-115$, doi: 10.1016/S0012-821X(98)00060-0. 
Kárason, H., and van der Hilst, R.D., 2001, Tomographic imaging of the lowermost mantle with differential times of refracted and diffracted core phases (PKP, Pdiff): Journal of Geophysical Research, v. 106, p. 6569-6588, doi: 10.1029/2000JB900380.

Karki, B.B., Wentzcovitch, R.M., de Gironcoli, S., and Baroni, S., 1999, Firstprinciples determination of elastic anisotropy and wave velocities of $\mathrm{MgO}$ at lower mantle conditions: Science, v. 286, p. 1705-1709, doi: 10.1126/ science.286.5445.1705.

Kellogg, L.H., Hager, B.H., and van der Hilst, R.D., 1999, Compositional stratification in the deep mantle: Science, v. 283, p. 1881-1884, doi: 10.1126/ science.283.5409.1881.

Kendall, J.-M., 2000, Seismic anisotropy in the boundary layers of the mantle, in Karato, S.-I., et al., eds., Earth's deep interior: Mineral physics and tomography from the atomic to the global scale: Washington, D.C., American Geophysical Union, p. 133-159.

Kendall, J.-M., and Silver, P.G., 1998, Investigating causes of D" anisotropy, in Gurnis, M., et al., eds., The core-mantle boundary region: Washington, D.C., American Geophysical Union, p. 97-118.

Kuo, C., and Romanowicz, B., 2002, On the resolution of density anomalies in the Earth's mantle using spectral fitting of normal mode data: Geophysical Journal International, v. 150, p. 162-179, doi: 10.1046/j.1365-246X.2002 .01698.x.

Lay, T., 2005, The deep mantle thermo-chemical boundary layer: The putative mantle plume source, in Foulger, G.R., et al., eds., Plates, plumes and paradigms: Boulder, Colorado, Geological Society of America Special Paper 388, p. 193-205.

Lay, T., Garnero, E.J., Williams, Q., Kellogg, L., and Wysession, M.E., 1998, Seismic wave anisotropy in the $\mathrm{D}^{\prime \prime}$ region and its implications, in Gurnis, M., et al., eds., The core-mantle boundary region: Washington, D.C., American Geophysical Union, p. 299-318.

Lay, T., Heinz, E., Ishii, M., Shim, S.H., Tsuchiya, T., Tsuchiya, J., Wentzcovich, R., and Yuen, D., 2005, Multidisciplinary impact of the lower mantle perovskite phase transition: Transactions of the American Geophysical Union, v. 86 , p. $1-5$.

Lay, T., Hernlund, J., Garnero, E.J., and Thorne, M.S., 2006, A post-perovskite lens and D" heat flux beneath the central Pacific: Science, v. 314, p. 1272 1276, doi: 10.1126/science.1133280.

Lin, S., and van Keken, P.E., 2005, Multiple volcanic episodes of flood basalts caused by thermochemical mantle plumes: Nature, v. 436, p. 250-252, doi: 10.1038/nature03697.

Lithgow-Bertelloni, C., and Richards, M.A., 1998, The dynamics of Cenozoic and Mesozoic plate motions: Reviews of Geophysics, v. 36, p. 27-78, doi: 10.1029/97RG02282.

Luo, S.-N., Ni, S., and Helmberger, D.V., 2001, Evidence for a sharp lateral variation of velocity at the core-mantle boundary from multipathed PKPab: Earth and Planetary Science Letters, v. 189, p. 155-164, doi: 10.1016/ S0012-821X(01)00364-8.

Mainprice, D., Barruol, G., and Ben Ismail, W., 2000, The seismic anisotropy of the Earth's mantle: From single crystal to polycrystal, in Karato, S.-I., et al., eds., Earth's deep interior: Mineral physics and tomography from the atomic to the global scale: Washington, D.C., American Geophysical Union, p. 237-264

Masters, G., and Gubbins, D., 2003, On the resolution of density within the Earth: Physics of the Earth and Planetary Interiors, v. 140, p. 159-167, doi: 10.1016/j.pepi.2003.07.008.

Masters, G., Laske, G., Bolton, H., and Dziewonski, A.M., 2000, The relative behavior of shear velocity, bulk sound speed, and compressional velocity in the mantle: Implications for chemical and thermal structure, in Karato, S.-I., et al., eds., Earth's deep interior: Mineral physics and tomography from the atomic to the global scale: Washington, D.C., American Geophysical Union, p. 63-87.

McNamara, A.K., and Zhong, S., 2004a, Thermochemical structures within a spherical mantle: Superplumes or piles?: Journal of Geophysical Research, v. 109, p. B07402, doi: 10.1029/2003JB002847.

McNamara, A.K., and Zhong, S., 2004b, The influence of thermochemical con- vection on the fixity of mantle plumes: Earth and Planetary Science Letters, v. 222, p. 485-500, doi: 10.1016/j.eps1.2004.03.008.

McNamara, A.K., and Zhong, S., 2005, Thermochemical piles under Africa and the Pacific: Nature, v. 437, p. 1136-1139, doi: 10.1038/nature04066.

McNamara, A.K., Karato, S.-I., and van Keken, P.E., 2001, Localization of dislocation creep in the lower mantle: Implications for the origin of seismic anisotropy: Earth and Planetary Science Letters, v. 191, p. 85-99, doi: 10.1016/S0012-821X(01)00405-8.

McNamara, A.K., van Keken, P.E., and Karato, S.-I., 2002, Development of anisotropic structure in the Earth's lower mantle by solid-state convection: Nature, v. 416, p. 310-314, doi: 10.1038/416310a.

McNamara, A.K., van Keken, P.E., and Karato, S.-I., 2003, Development of finite strain in the convecting lower mantle and its implications for seismic anisotropy: Journal of Geophysical Research, v. 108, p. 2230, doi: 10.1029/ 2002JB001970.

Mégnin, C., and Romanowicz, B., 2000, The shear velocity structure of the mantle from the inversion of body, surface, and higher modes waveforms: Geophysical Journal International, v. 143, p. 709-728, doi: 10.1046/j.1365246X.2000.00298.x

Mitrovica, J.X., and Forte, A.M., 1997, Radial profile of mantle viscosity: Results from joint inversion of convection and post-glacial rebound observables: Journal of Geophysical Research, v. 102, p. 2751-2769, doi: 10.1029/96JB03175.

Montelli, R., Nolet, G., Dahlen, F.A., Masters, G., Engdahl, E., and Hung, S., 2004, Finite-frequency tomography reveals a variety of plumes in the mantle: Science, v. 303, p. 338-343, doi: 10.1126/science. 1092485.

Montelli, R., Nolet, G., Dahlen, F.A., and Masters, G., 2006, A catalogue of deep mantle plumes: New results from finite-frequency tomography: Geochemistry, Geophysics, and Geosystems, v. 7, p. Q11007, doi: 10.1029/2006 GC001248.

Morgan, W.J., 1971, Convection plumes in the lower mantle: Nature, v. 230, p. 42-43, doi: 10.1038/230042a0.

Murakami, M., Hirose, K., Kawamura, K., Sata, N., and Ohishi, Y., 2004, Postperovskite phase transition in $\mathrm{MgSiO}_{3}$ : Science, v. 304, p. 855-858, doi: 10.1126/science. 1095932

Nakagawa, T., and Tackley, P.J., 2005, The interaction between the postperovskite phase change and a thermo-chemical boundary layer near the core-mantle boundary: Earth and Planetary Science Letters, v. 238, p. 204 216, doi: 10.1016/j.eps1.2005.06.048.

Nataf, H.-C., 2000, Seismic imaging of mantle plumes: Annual Review of Earth and Planetary Sciences, v. 28, p. 391-417, doi: 10.1146/annurev.earth .28.1.391.

Ni, S., and Helmberger, D.V., 2001, Horizontal transition from fast (slab) to slow (plume) structures at the core-mantle boundary: Earth and Planetary Science Letters, v. 187, p. 301-310, doi: 10.1016/S0012-821X(01) 00273-4.

Ni, S., and Helmberger, D.V., 2003a, Seismological constraints on the South African superplume; Could be the oldest distinct structure on Earth: Earth and Planetary Science Letters, v. 206, p. 119-131, doi: 10.1016/S0012821X(02)01072-5.

Ni, S., and Helmberger, D.V., 2003b, Ridge-like lower mantle structure beneath South Africa: Journal of Geophysical Research, v. 108, p. 2094, doi: 10.1029/2001JB001545.

Ni, S., Tan, E., Gurnis, M., and Helmberger, D.V., 2002, Sharp sides to the African superplume: Science, v. 296, p. 1850-1852, doi: 10.1126/science .1070698 .

Oganov, A.R., and Ono, S., 2004, Theoretical and experimental evidence for a post-perovskite phase of $\mathrm{MgSiO}_{3}$ in Earth's D" layer: Nature, v. 430, p. 445-448, doi: 10.1038/nature02701.

Ohta, K., Hirose, K., Lay, T., Sata, N., and Ohishi, Y., 2007, Evidence for a MORB-rich pile above the Earth's core-mantle boundary: Proceedings of the National Academy of Sciences, USA, in press.[AQ1]

Olson, P., and Kincaid, C., 1991, Experiments on the interaction of thermal convection and compositional layering at the base of the mantle: Journal of Geophysical Research, v. 96, p. 4347-4354. 
Revenaugh, J.S., and Meyer, R., 1997, Seismic evidence of partial melt within a possibly ubiquitous low-velocity layer at the base of the mantle: Science, v. 277 , p. 670-673, doi: 10.1126/science.277.5326.670.

Ritsema, J., and van Heijst, H.J., 2000, Seismic imaging of structural heterogeneity in Earth's mantle: Evidence for large-scale mantle flow: Science Progress, v. 83, p. 243-259.

Ritsema, J., McNamara, A.K., and Bull, A.L., 2007, Tomographic filtering of geodynamic models: Implications for model interpretation and large-scale mantle structure: Journal of Geophysical Research, v. 112, p. B01303, doi: 10.1029/2006JB004566.

Rokosky, J., Lay, T., and Garnero, E.J., 2006, Small-scale lateral variations in azimuthally anisotropic $\mathrm{D}^{\prime \prime}$ structure beneath the Cocos plate: Earth and Planetary Science Letters, v. 248, p. 411-425, doi: 10.1016/j.eps1.2006 .06 .005 .

Romanowicz, B., 2001, Can we resolve 3D density heterogeneity in the lower mantle?: Geophysical Research Letters, v. 28, p. 1107-1110.

Rost, S., and Revenaugh, J.S., 2001, Seismic detection of rigid zones at the top of the core: Science, v. 294, p. 1911-1914, doi: 10.1126/science.1065617.

Rost, S., Garnero, E.J., Williams, Q., and Manga, M., 2005, Seismic constraints on a possible plume root at the core-mantle boundary: Nature, v. 435, p. 666-669, doi: 10.1038/nature03620.

Rost, S., Garnero, E.J., and Williams, Q., 2006, Fine scale ultra-low velocity zone structure from high-frequency seismic array data: Journal of Geophysical Research, v. 111, p. B09310, doi: 10.1029/2005JB004088.

Rost, S., Garnero, E.J., and Williams, Q., 2007, Seismic array detection of subducted oceanic crust in the lower mantle: Earth and Planetary Science Letters, in press.[AQ2]

Russell, S.A., Lay, T., and Garnero, E.J., 1998, Seismic evidence for small-scale dynamics in the lowermost mantle at the root of the Hawaiian hotspot: Nature, v. 396, p. 255-258, doi: 10.1038/24364.

Schubert, G., Masters, G., Olson, P., and Tackley, P.J., 2004, Superplumes or plume clusters?: Physics of the Earth and Planetary Interiors, v. 146, p. 147-162, doi: 10.1016/j.pepi.2003.09.025.

Sleep, N.H., 2007 (this volume), Origins of the plume hypothesis and some of its implications, in Foulger, G.R., and Jurdy, D.M., eds., Plates, plumes, and planetary processes: Boulder, Colorado, Geological Society of America Special Paper 430, doi: 10.1130/2007.2430(02).

Steinberger, B., 2000, Plumes in a convecting mantle: Models and observations for individual hotspots: Journal of Geophysical Research, v. 105, p. 11,12711,152, doi: 10.1029/1999JB900398.

Stixrude, L., 1998, Elastic constants and anisotropy of $\mathrm{MgSiO}_{3}$ perovskite, periclase, and $\mathrm{SiO}_{2}$ at high pressure, in Gurnis, M., et al., eds., The coremantle boundary region: Washington, D.C., American Geophysical Union, p. 83-96.

Su, W.J., and Dziewonski, A.M., 1997, Simultaneous inversion for 3-D variations in shear and bulk velocity in the mantle: Physics of the Earth and Planetary Interiors, v. 100, p. 135-156, doi: 10.1016/S0031-9201(96)03236-0.

Tackley, P.J., 1998, Three-dimensional simulations of mantle convection with a thermochemical CMB boundary layer: $\mathrm{D}^{\prime \prime}$ ?, in Gurnis, M., et al., eds., The core-mantle boundary region: Washington, D.C., American Geophysical Union, p. 231-253.

Tackley, P.J., 2002, Strong heterogeneity caused by deep mantle layering: Geochemistry, Geophysics, and Geosystems, v. 3, p. 1024, doi: 10.1029/2001 GC000167.

Tan, E., and Gurnis, M., 2005, Metastable superplumes and mantle compressibility: Geophysical Research Letters, v. 32, p. L20307, doi: 10.1029/2005 GL024190.

Thorne, M., and Garnero, E.J., 2004, Inferences on ultralow-velocity zone structure from a global analysis of SPdKS waves: Journal of Geophysical Research, v. 109, p. B08301, doi: 10.1029/2004JB003010.

Thorne, M., Garnero, E.J., and Grand, S., 2004, Geographic correlation between hot spots and deep mantle lateral shear-wave velocity gradients: Physics of the Earth and Planetary Interiors, v. 146, p. 47-63, doi: 10.1016/j.pepi. 2003.09.026.

Tilmann, F.J., McKenzie, D., and Priestley, K.F., 1998, P and S wave scattering from mantle plumes: Journal of Geophysical Research, v. 103, p. 21,14521,163, doi: 10.1029/98JB01070.

To, A., Romanowicz, B., Capdeville, Y., and Takeuchi, N., 2005, 3D effects of sharp boundaries at the borders of the African and Pacific superplumes: Observation and modeling: Earth and Planetary Science Letters, v. 233, p. 137-153, doi: 10.1016/j.eps1.2005.01.037.

Trampert, J., Deschamps, F., Resovsky, J., and Yuen, D.A., 2004, Probabilistic tomography maps chemical heterogeneities throughout the mantle: Science, v. 306, p. 853-856, doi: 10.1126/science.1101996.

Tsuchiya, T., Tsuchiya, J., Umemoto, K., and Wentzcovitch, R.M., 2004, Phase transition in $\mathrm{MgSiO}_{3}$ perovskite in the Earth's lower mantle: Earth and Planetary Science Letters, v. 224, p. 241-248, doi: 10.1016/j.eps1.2004 .05 .017 .

van der Hilst, R.D., Widyantoro, S., and Engdahl, E.R., 1997, Evidence for deep mantle circulation from global tomography: Nature, v. 386, p. 578-584, doi: $10.1038 / 386578 \mathrm{a} 0$.

van Keken, P.E., 1997, Evolution of starting mantle plumes: A comparison between numerical and laboratory models: Earth and Planetary Science Letters, v. 148, p. 1-11, doi: 10.1016/S0012-821X(97)00042-3.

Vidale, J.E., and Hedlin, M.A.H., 1998, Evidence for partial melt at the coremantle boundary north of Tonga from the strong scattering of seismic waves: Nature, v. 391, p. 682-685, doi: 10.1038/35601.

Wang, Y., and Wen, L., 2004, Mapping the geometry and geographic distribution of a very-low velocity province at the base of the Earth's mantle: Journal of Geophysical Research, v. 109, p. B10305, doi: 10.1029/2003 JB002674

Wen, L., 2000, Intense seismic scattering near the Earth's core-mantle boundary beneath the Comoros hotspot: Geophysical Research Letters, v. 27, p. 3627-3630, doi: 10.1029/2000GL011831.

Wen, L., 2006, A compositional anomaly at the Earth's core-mantle boundary as an anchor to the relatively slowly moving surface hotspots and as source to the DUPAL anomaly: Earth and Planetary Science Letters, v. 246, p. 138-148, doi: 10.1016/j.eps1.2006.04.024.

Wen, L., and Helmberger, D.V., 1998, Ultra-low velocity zones near the coremantle boundary from broadband PKP precursors: Science, v. 279, p. 1701-1703, doi: 10.1126/science.279.5357.1701.

Wen, L., Silver, P., James, D., and Kuehnel, R., 2001, Seismic evidence for a thermo-chemical boundary layer at the base of the Earth's mantle: Earth and Planetary Science Letters, v. 189, p. 141-153, doi: 10.1016/S0012821X(01)00365-X.

Wentzcovitch, R.M., Karki, B.B., Cococcioni, M., and de Gironcoli, S., 2004, Thermoelastic properties of $\mathrm{MgSiO}_{3}$-perovskite: Insights on the nature of the Earth's lower mantle: Physical Review Letters, v. 92, p. 0185011-018501-4, doi: 10.1103/PhysRevLett.92.018501.

Wessel, P., and Smith, W.H.F., 1998, New, improved version of Generic Mapping Tools released: Eos (Transactions, American Geophysical Union), v. 79, p. 579, doi: 10.1029/98EO00426.

Williams, Q., and Garnero, E.J., 1996, Seismic evidence for partial melt at the base of Earth's mantle: Science, v. 273, p. 1528-1530, doi: 10.1126/science .273.5281.1528.

Williams, Q., Revenaugh, J.S., and Garnero, E.J., 1998, A correlation between ultra-low basal velocities in the mantle and hot spots: Science, v. 281, p. 546-549, doi: 10.1126/science.281.5376.546.

Wookey, J., Kendall, J.-M., and Rumpker, G., 2005, D" anisotropy from differential S-ScS splitting: Geophysical Journal International, v. 161, p. 829838, doi: 10.1111/j.1365-246X.2005.02623.x.

Wysession, M.E., Bartkó, L., and Wilson, J.B., 1994, Mapping the lowermost mantle using core-reflected shear waves: Journal of Geophysical Research, v. 99 , p. 13,667-13,684, doi: 10.1029/94JB00691.

Zhao, D., 2001, Seismic structure and origin of hotspots and mantle plumes: Earth and Planetary Science Letters, v. 192, p. 251-265, doi: 10.1016/ S0012-821X(01)00465-4.

Manuscript Accepted by the Society 31 JANUARY 2007 


\section{DISCUSSION}

\section{December 2006, Don L. Anderson}

If someone points out to you that your pet theory of the universe is in disagreement with Maxwell's equations-then so much the worse for Maxwell's equations. If it is found to be contradicted by observationwell, these experimentalists do bungle things sometimes. But if your theory is found to be against the second law of thermodynamics I can give you no hope; there is nothing for it but to collapse in deepest humiliation."

Sir Arthur Stanley Eddington, The nature of the physical world (1915).

Most scientific paradigms survive until a better paradigm comes along. Rarely, a paradigm is abandoned because some overlooked physics shows that it is impossible, or improbable. The concepts of Ptolemy, aether, phlogiston, and caloric, the most famous of the classical physics paradigm shifts, occurred when the concepts became so contrived and convoluted that people lost interest. But an idea that violates thermodynamics should be abandoned immediately. Seismological studies paired with fluid injection experiments and Boussinesq simulations cannot answer the question of whether the lowermost mantle is a plausible source for surface hotspots. Low velocities, high velocities, ultraslow velocities, and anisotropy have all been used as " 'evidence' " for plumes (see the references in Garnero et al., this volume). Plumes have been proposed to emanate from the tops of superplumes, rather from $D^{\prime \prime}$. We have also been told that lack of clear tomographic evidence for plumes in the lower mantle is due to lack of resolution or coverage. Now we are told that the most likely locations of mantle plumes are over the boundaries between slow and fast regions. There is no way that the plume hypothesis can be falsified with these many and contradictory options. So much for the observational aspect. The commonly used Boussinesq approximation for mantle convection is not as soundly based as Maxwell's equations, and it certainly ignores thermodynamics. A thermal boundary layer (TBL) at the base of the mantle certainly exists, but this is not a sufficient condition to form deep narrow plumes, as currently envisaged. A TBL serves to conduct heat out of the core, but whether it can form sufficiently buoyant plume heads to break out of the lower mantle, or develop 100- to 200-km-wide plume tails in a reasonable amount of time depends on the material parameters, which depend on composition, pressure, core heat, mantle radioactivity, and convective vigor. If the local Rayleigh number is less than about 1000, the TBL will not go unstable. If the coefficient of thermal expansion is low, the TBL may never develop enough buoyancy to escape. When pressure is taken into account, the dimensions of buoyant instabilities are on the order of thousands, not hundreds, of kilometers. If the intrinsic density of $\mathrm{D}^{\prime \prime}$ is as little as $1 \%$ higher than the rest of the mantle, it will be permanently trapped, but this does not mean that it will have a simple structure. It is surprising that none of the discussions in this volume that argue for deep-mantle plumes mention the effects of pressure on material properties and the ability of internal heating and background mantle convention to prevent or destroy the instabilities.

As long as heat is flowing into the base of the mantle, a TBL should be present, but the ratio of core heat to mantle heat and the local (pressure-dependent) Rayleigh number are the key parameters, not the mere existence of a TBL. Cylindrical plumes in numerical and laboratory experiments usually involve localized basal heating, the instantaneous creation of a hot sphere, or basal injection of fluid; pressure and background convection effects are ignored and thermal effects exaggerated (see, e.g., the articles by Sleep, this volume, and King and Redmond, this volume). The "expected small plume conduit dimension (e.g., $<500$ $\mathrm{km}[\mathbf{A Q 3}]$ )" is based on experiments that ignore pressure effects or that impose the dimension ("experimentalists do bungle things sometimes").

The smoking gun against deep-mantle plumes is thermodynamics. All the critical thermodynamic parameters depend on volume, but these are ignored in all calculations that yield narrow whole-mantle plumes (the Boussinesq approximation). None of the fluid dynamic calculations used by the authors to support their view take into account the effect of pressure on thermal expansivity and its role in chemically stratifying the mantle and stabilizing deep thermal structures. The few non-Boussinesq calculations that have been done do not use self-consistent thermodynamic relations, but even so, they do not predict plumelike dimensions and timescales at $\mathrm{D}^{\prime \prime}$ depths. At upper-mantle pressures, thermal expansivity is high, and chemical stratification is reversible. However, simple scaling relations show that pressure increases conductivity and viscosity — and spatial and temporal scales - and decreases the coefficient of thermal expansion and the local Rayleigh number. Even slight compositional effects can make deep dense layers permanent and complex.

\section{December 2006, Geoffrey F. Davies}

The factor that invalidates Anderson's claims is the temperature dependence of viscosity. It is the reason plumes form head-andtail structures, as illustrated in Davies (1999). The effect is actually considerably stronger at higher pressure, because the activation enthalpy may be two or three times larger at the base of the mantle than near the surface. Plume heads are large mainly because they have to displace high-viscosity surroundings to rise, but plume tails can be narrow, because the lower-viscosity plume fluid can flow up a pre-existing path. The other factors Anderson mentions have some effect but are not dominant.

The problems with Anderson's arguments were detailed in Davies (2005). Either Davies's criticisms should be refuted or Anderson's arguments should not be repeated, because they appear to be quite invalid. By the way, plenty of plume models have been done with uniform basal heating; see, for example, Davies (1999) and Leitch and Davies (2001). 


\section{December 2006, Don L. Anderson}

I thank Geoff Davies for providing these references and allowing me to clear up possibly confusing points. He has put his finger on the essence of the issue separating those who think mantle plumes are obvious and inevitable from those who remain skeptical of their physical basis. The issue regarding the temperature dependence of viscosity is not straightforward and is regarded as a paradox (e.g., Nataf, 1991; Lenardic and Kaula, 1994). When this effect is taken into account - in its entirety-the upper TBL becomes thicker, making the upper mantle hotter, and the lower mantle acquires a negative or subadiabatic temperature gradient; the lower TBL becomes colder. Melting is more likely to occur in the upper mantle, and to greater depths, than is the case with constant viscosity. Cavity plumes are less likely to form at the base of the system unless the boundary layers interact.

The temperature dependence of viscosity is a two-edged sword. If applied to the lower TBL in isolation, it would seem to make cavity plumes more likely. But it also makes the upper TBL stiffer, longer-lived, and with a larger temperature drop. When this upper layer goes unstable, it cools the lower mantle and the lower TBL, making them stiffer (Lenardic and Kaula, 1994). Much of the lower mantle develops a subadiabatic or negative temperature gradient because of internal heating and slab cooling, increasing the viscosity with depth. Ironically, it has been argued that hot plumes from the deep TBL will heat and thin the plate, but sinking of the cold surface TBL and cooling of the base of the system, the parallel effect, has been ignored and may be more important, because of the temperature dependence of viscosity!

When the possibilities of melting and differentiation are allowed for in a convection calculation, the mantle can become chemically stratified (Tackley and Xie, 2002). The various components (e.g., eclogite and refractory residue in this case) collect or re-collect at levels of neutral buoyancy and survive or regenerate there for billions of years (see also Anderson, this volume). Buoyant material in the shallow mantle also extends the surface TBL, making the upper mantle hotter still. Chemical layering is facilitated by pressure dependence of thermal properties and reduces the Rayleigh number and the vigor of convection, particularly at depth.

The equations in Davies (2005) regarding the effect of temperature and pressure on viscosity are identical to those in Chapter 7 of Theory of the Earth (Anderson, 1989). There is no disagreement there. The standard Arrhenius form and the various terms - the pre-exponential, the activation volume, and the activation energy - are derived. It was determined (Anderson, 1989 , p. 133) that the viscosity should increase by about a factor of 60 to 80, due to compression across the lower mantle, at constant $T$. The total variation across the mantle involves a large decrease due to the temperature rise in the upper mantle and a possibly smaller decrease at the lower TBL. The mid-mantle effect is uncertain. The viscosity jump across discontinuities may be negative.
As Davies points out, there are many calculations in the plume literature of uniform bottom heating, and also of localized heating and injections of hot fluid. If we have only bottom heating, no pressure effects, and no radioactivity, then plumes are inevitable if the heating is strong enough; the core is the only heat source in this model and its heat is removed by plumes. But plumes, plates and convection, and $\mathrm{D}^{\prime \prime}$ should not be treated separately (Lenardic and Kaula, 1994). The papers by Tozer (1973), Kaula (1983), Nataf (1991), Lenardic and Kaula (1994), and Tackley and Xie (2002) collectively make the point that one cannot treat one variable (viscosity), one parameter (temperature), one region of the mantle $\left(\mathrm{D}^{\prime \prime}\right)$, one mode of heating and/or cooling (core heat), or one boundary condition independently; the whole parameter space and system must be treated together, in a self-consistent way. This is required by thermodynamics and farfrom-equilibrium systems, such as convection.

All simulations of narrow plumes involve injection of hot fluid through a circular orifice, uniform or localized heating from below, or the instantaneous creation of a hot sphere as the initial condition; plumes and their dimensions are imposed by the investigator, rather than being natural fluid dynamic instabilities in a realistic setup that resembles the mantle. In other studies, a plume is just assumed to exist and its properties are investigated.

The five remarkable papers cited above, mostly overlooked, plus Theory of the Earth (Anderson, 1989), form the basis of the present discussion. Petrology and self-consistent fluid dynamics appear to explain the thick average TBL thickness $(280 \mathrm{~km})$ and the mean mantle potential temperature $\left(1410 \pm 180^{\circ} \mathrm{C}\right)$ derived by Kaula (1983) from geophysical and plate tectonic data. These values exceed expectations from cooling of a homogeneous fluid or the temperatures of mid-ocean ridge basalt (MORB). The temperatures and depths are consistent with 'hotspot' magmas being derived from within or just below the surface TBL, but do not rule out the existence of fertile blobs (Anderson, this volume; Beutel and Anderson, this volume),

\section{December 2006, Geoffrey F. Davies}

Anderson's points are either invalid, confused, or make little difference.

Upper TBL. A temperature-dependent viscosity can stiffen the top TBL, make it thicker, and raise the internal temperature. However this is only true if the TBL becomes immobile (stagnant lid regime). The mantle's top TBL is mobile, because it is broken into moving plates that can subduct. In this case Anderson's arguments do not apply, though they would in any case only change the details, not the general principles described below. Besides, how could you reconcile a 280-km-thick TBL with seismological constraints on the thickness of the oceanic lithosphere, and with seafloor subsidence and heat flow? I think you cannot.

Subadiabatic Gradient. It is well known that the vertical temperature gradient between TBLs is subadiabatic, regardless 
of heating mode or the nature of the top TBL. Recent estimates are that the temperature is $100-300^{\circ} \mathrm{C}$ lower than adiabatic near the bottom of the mantle. This temperature reduction will raise the viscosity significantly relative to an adiabatic profile, as Anderson says, but it is only part of the uncertainty in deep-mantle viscosity, as I discuss below.

Bottom TBL and Plume Formation. The viscosity and temperature above the bottom TBL are not the only determinants of whether plumes will occur. The other major determinant is the temperature at the core-mantle boundary, which changes only on billion-year timescales. The minimum viscosity in the TBL occurs at this boundary, and is likely to be two to five orders of magnitude lower than the overlying ambient mantle, depending on the temperature increase through the boundary layer, which is commonly estimated to be $1000^{\circ} \mathrm{C}$ or more. Even an increase of $500^{\circ} \mathrm{C}$ is ample to generate plumes (Leitch, 2001[AQ4]).

The role of the viscosity above the TBL is to control the timing and size of an instability that can begin to rise- the larger the viscosity, the larger the blob must be before it can detach (Griffiths and Campbell, 1990; Davies, 1999). Once a blob is detached and rising, the behavior of material following from the TBL depends on its viscosity, which, as noted above, depends on the core-mantle boundary temperature, not the temperature above the TBL. Because it is likely to be two or more orders of magnitude lower in viscosity, it will form a narrow conduit, as noted in previous discussion and demonstrated by Davies (1999).

The viscosity above the TBL could be changed by one to two orders of magnitude without changing this general behavior. Only quantitative details would change, such as the exact dimensions of the initial head and the following tail.

If the lower mantle were cooler and more viscous than we have thought, as Anderson advocates, then the temperature difference between the mantle and core would be greater, which would cause stronger plumes. The higher viscosity would mean the plume heads took longer to develop and would be larger.

Viscosity Increase through the Lower Mantle. Anderson's discussion of the depth dependence of viscosity seems to be confused. Mid-mantle viscosity is constrained by post-glacial rebound and subduction zone geoids to be around $10^{22} \mathrm{~Pa} \mathrm{~s}$ (e.g., Mitrovica, 1996). Deep-mantle viscosity is unlikely to be much more than an order of magnitude greater than this value, or it would affect the rebound or Earth's rotation noticeably.

I do not know how Anderson gets an isothermal increase of viscosity by only a factor of 60-80 over the lower mantle from his formulas. His $(\partial \ln \eta / \partial \ln \rho)=40-48$ [AQ5]( $\eta$ is viscosity, and $\rho$ is density) and a density increase from 4400 to $5500 \mathrm{~kg} / \mathrm{m}^{3}$ through the lower mantle yields an increase by a factor of 7500-44,000. This increase is larger than the observational constraints seem to permit, so evidently these formulas are not good guides (e.g., Davies, 2005).

Anderson's isothermal increase by a factor of 60-80 (Anderson, 1989) would seem to imply little increase or even a decrease along the actual (subadiabatic) mantle temperature profile, which would not serve his cause of suppressing mantle plumes.
Anderson's formula for viscosity on p. 133 of his book (Anderson, 1989), to which he refers, is not correct: viscosity $(\mathrm{G} / \sigma) n^{\prime} n=1-3$ ( $\sigma$ is deviatoric stress). If $\mathrm{G}$ is the rigidity (shear modulus) as used on the previous page, then this ratio is dimensionless. Presumably Anderson meant strain rate $\sim(\sigma / G)^{n}$, which yields viscosity $\sim\left(\mathrm{G}^{n} / \sigma^{(n-1)}\right)$. Even so, this term is only one factor in the full expression for strain rate (see equation 6.10.3 in Davies, 1999). $\mathrm{G}$ is a useful scaling factor, not a rigorous predictor. Similarly, Anderson's equation relating activation volume to the depth dependence of $\mathrm{G}$ on the previous page is no more than a rough, possibly very rough guide, given the sensitivity of viscosity to activation volume.

Uniform Bottom Heating. Anderson lumps uniform bottom heating in with other types of boundary condition and repeats his claim that modelers' boundary conditions have predetermined plumes and their dimensions, rather than leaving the fluid dynamics to determine the outcome. Let it be clear: uniform bottom heating does not determine plume dimensions or other characteristics - it leaves that to the fluid dynamics.

The amount of bottom heating does predetermine the occurrence of plumes, it is true, and that is because the physics requires them under the conditions prescribed. Those conditions are, in the better experiments (laboratory or numerical), tailored to the conditions near the core-mantle boundary, as best we understand them. Anderson has yet to make a persuasive case that those conditions might be very different.

Anderson does a disservice to modelers by claiming or implying that other factors have not been considered, such factors as changes of properties with depth, radioactivity, and the existence of another TBL. They have. If one understands the physics, one can sensibly understand the usefulness and relevance of the models. Furthermore, it is not true that modelers have not included a vertical viscosity gradient in their lower mantles-they have.

If the Hawaiian hotspot chain did not exist, and if several hotspot chains did not emerge from flood basalt provinces, there might be some point to the debate, but models of thermal plumes give a good quantitative account of those phenomena. I do not, however, claim that thermal plumes can explain everything (see Davies, 2005).

General Comment. The physics of thermal convection, and of plumes in particular, is well understood and not too hard to follow. Readers are referred to Davies (1999). The points made here have been made before. The productive debates have moved on to other things, such as the role of compositional variations and the influence of subduction.

\section{December 2006, Don L. Anderson}

What the general reader of these pages wants to know is: does fluid dynamics prove that mantle plumes must exist, and does it rule out alternative explanations for melting anomalies? Davies and I both agree that it does neither. Are self-consistent, selforganized simulations better than ad hoc parameters and tightly 
constrained experiments? Yes. Does the newly found complexity in $\mathrm{D}^{\prime \prime}$ imply that the source of plumes has been found? Is the mantle almost entirely heated from below? Of course not. When we look at volcanoes can we ignore the lowermost mantle? Are the early arguments, assumptions, predictions, and experiments for plumes still valid? Is it possible that the shallow mantle is hotter and more variable in fertility and melting point than generally assumed? Here, Davies and I diverge.

The best way for the nonspecialist to understand these issues is to look at the series of calculations published, for example, by Tackley (1998, 2002), Lowman et al. (2001), Davies (2005), and Phillips and Bunge (2005), who demonstrate the extreme sensitivity to initial and boundary conditions that is characteristic of nonlinear chaotic systems. These investigators usually start with the simple case discussed by Davies (2005), Leitch and Davies (2001), and Campbell and Davies (2006) (hereafter DLC) — bottom heating with constant properties. Nice little mushroom forests appear, as expected. Then radioactive heating is introduced, and temperature- and depth-dependent properties, and then, continents. The mushrooms disappear and the mantle heats up and becomes unsteady. Then melting and differentiation are introduced. Layers and blobs appear. Then large plates and large-aspect-ratio convection cells are allowed. The mantle gets hotter still and fusible blobs melt. Then secular cooling is thrown in. The whole system changes as each new element is introduced, which is the nature of self-organized, far-from-equilibrium or chaotic systems. The system also flips spontaneously from one state to another.

The plates may control mantle temperature. In some cases, the system jams and heats up, and one has to crack the plates to allow subduction, and the whole mantle reorganizes again. The lower TBL is cooled if the plates sink to the bottom. Modelers who have got this far do not much discuss narrow, hot, stationary, long-lived, or radial plumes. The mantle is plenty hot, fertile, and variable, so that many alternative explanations of melting anomalies are now on the table. The claims that narrow plumes are an inevitable result of a TBL, that plumes are the way the core gets rid of its heat, and that hotspots are independent of other forms of mantle convection and plate tectonics have not received numerical validation, although calculations can easily be designed that satisfy these claims.

Delamination of the lower part of the plate, not yet included in any global simulation, can also fertilize and cool the mantle. When delamination occurs, warm asthenosphere rushes up to fill the gap and we get a volcano. When the delaminated blob heats up, it melts, and we can get another volcano or volcanic chain. The more realistic the fluid dynamics gets, the more plausible are layering, delamination, shallow return flow, and fertile blob mechanisms. In the extreme case, it is the outer shell that is the regulator, not mantle viscosity or even temperature.

These points are well illustrated in Phillips and Bunge (2005), Tackley and Xie (2002), Parmentier et al. (1994), Grigné et al. (2005), and Nakagawa and Tackley (2006). These are re- alistic mantle simulations (hereafter RMS) ${ }^{1}$ performed in wide boxes or spherical shells that can self-organize. These papers show how the various effects (internal heating, plates, continents, melting, layering, secular cooling, 3-D) affect the background temperatures and mantle motions that plumes must endure. Not surprisingly, these studies do not validate the results, assumptions, and boundary conditions in DLC. Plumes were initially proposed because of perceived shortcomings in the simplified convection and tectonic models existing at the time. It was then thought that the lower mantle was rigid or had very high viscosity, and that plates were rigid.

Bottom-heated, axisymmetric, and injection experiments (DLC) have been useful for understanding idealized thermal plumes. Indeed, it was these studies that caused the wider community to embrace the plume idea. Plumes were an elegant and easy-to-understand solution to midplate volcanism. However, it is a disservice to the wider community to imply that plumes must always exist, and that they provide the only explanation for Hawaii and the like, particularly as more realistic calculations (laboratory experiments cannot cover the appropriate conditions) plus lithologic heterogeneities provide alternative ways to form hot mantle and melting anomalies. For example, if the mantle is only $100^{\circ} \mathrm{C}$ hotter than assumed in the plume literature, and the melting point of blobs is $200^{\circ} \mathrm{C}$ lower, then plumes are not needed.

Realistic convection simulations confirm that the mantle runs hotter and more episodically than homogeneous or bottomheated models (Phillips and Bunge, 2005). Fe-enrichment in D" means that excess plume temperatures must be much higher than DLC assumes; otherwise, material cannot rise out of the region. Pressure-dependent properties do the same thing. Decreased thermal expansion coefficient and increased conductivity do not automatically preclude plumes, but the intrinsic density of $\mathrm{D}^{\prime \prime}$, its thickness, and its buoyancy parameter can preclude their escape. The required temperature contrasts may become larger than available. Even a 1-2\% density excess may stabilize $\mathrm{D}^{\prime \prime}$, but large structures are required to generate the buoyancy needed to make plumes rise.

Plate tectonics involves recycling and the introduction of low-melting-point constituents into the mantle, forming layers and blobs. A stiff outer shell prevents magmatism except where permitted by extension or delamination, and it also causes the temperature to rise. In other words, melting anomalies, the very reasons that plumes were introduced in the first place, are potentially explained by models with realistic properties and without plumes. An internally heated mantle, cooled from the top, will have large rising regions caused by slowly developing buoyancy and displacement by sinkers, but these are not plumes as conventionally defined; they are the normal convection that plumes were invented to augment.

\footnotetext{
${ }^{1}$ The RMS papers and associated figures can be found conveniently by inputting
} the search string author+convection into Google or Google Images. 
There are still surprises out there, as one expects in selforganized far-from-equilibrium systems that are allowed to do their own thing. A small change (one crack, one continent) can change everything, as elegantly shown by Gurnis, Bercovici, Phillips, Bunge, Tackley, Lenardic, Lowman, King, Hansen, Conrad, Hager, and their collaborators (see references on www .MantlePlumes.org). These authors have repeatedly reminded us that mantle convection is not only a branch of chaos theory but also a branch of thermodynamics; thus, all the parameters and boundary conditions are interconnected, and self-consistency is essential. RMS studies show that self-consistent models run hot and unsteadily, and have large plates and large aspect ratio convection. A single injection or axisymmetric experiment simply cannot be so generalized; too many degrees of freedom have been removed. Until the RMS calculations were done, we did not even ask whether the mantle organized the plates or the plates organized the mantle, or whether things oscillated. In bottom-heated cylinders, these issues are not even raised; one knows what will happen, and where.

It is interesting to note the progression in geodynamic thinking, from lower-boundary control (bottom heating, plumes) to mantle self-regulation (the Tozer effect) to control by the plates (plate bending, top-down tectonics). The top boundary condition, ignored or simplified until recently, may act as a template but may also organize and drive mantle convection, and localize magmatism. Fretting about details of $\mathrm{D}^{\prime \prime}$ may be beside the point for volcanoes if the upper mantle is as hot and variable as realistic simulations suggest.

\section{December 2006, Ed J. Garnero, Thorne Lay, and Allen McNamara}

We thank Don Anderson for his comments on our paper and Geoff Davies for his responses. First, let us reiterate that the purpose of our paper was to consider (not to prove or disprove) the possible connections between recent deep-mantle seismic findings, state-of-the-art numerical geodynamical calculations, and geographical systematics for upwellings and plume initiation. We drew attention to the remarkable seismic evidence for "sharp edges" to the large low-shear-velocity provinces (LLSVPs) in the deepest mantle (note our explicitly dynamically neutral terminology), which cannot be attributed solely to temperature gradients. Thus, a distinct chemical component to the LLSVPs is highly likely. This possibility motivates consideration of implications of thermochemical boundary layers for plume initiation in contrast to the standard isochemical TBL behavior discussed in most plume scenarios.

Although we discussed studies that advance the interpretation that LLSVPs are "superplumes" that rise in the mantle because of intrinsic thermal or chemical buoyancy, we do not advocate such models. The fact that LLSVPs are not beneath past or present subduction locations is consistent with subduction-related currents sweeping the LLSVP material into "piles" and maintaining their strong lateral margins (between LLSVP material and adjacent non-LLSVP mantle). In this scenario, the deep mantle must have significant convection currents. We appeal to a density increase of the LLSVPs, as suggested by a few seismic studies, recognizing that this increase is an issue of debate. Thus, our article takes the perspective that LLSVPs are relatively stable deep-mantle features with configurations sustained by the past few hundred million years of mantle circulation. Thus, some connection between deep mantle and surface structures is worth examining.

Geographically correlating phenomena at the top and bottom of the mantle certainly leaves one wanting better constraints on structure between the boundaries of the mantle. The reduction of seismic resolution in the mid-mantle (compared to the upper and lower boundary layers) cannot be used for or against any favored hypothesis. Nonetheless, it is significant that commonly designated hotspot populations are twice as likely to overlie the regions of strongest $\mathrm{D}^{\prime \prime}$ lateral shear-velocity gradients than regions with the lowest velocities. They are increasingly unlikely to overlie regions with high velocities (Thorne et al., 2004). The strongest shear-velocity gradients in tomographic studies are coincident with LLSVP edges; thus, hotspots are observationally more likely to be situated above LLSVP edges. We recognize the difficult issue of what one calls a "hotspot" (e.g., Courtillot et al., 2003), but that problem is beyond the scope of our current article. The thermochemical geodynamic calculations driven by historical subduction patterns result in configurations of large chemical piles in close accord with seismic observations and predict concentrations of TBL instabilities on the margins of the piles, as hot boundary layer material is swept up onto the pile edges. Thus, the seismic observations, geodynamic models, and crude correlations with surface phenomena give a provocative new perspective on how deep-mantle heterogeneity may plausibly influence some surface volcanism.

Anderson points out that the geodynamic calculations we consider involve approximations; in particular, pressure dependence of the coefficient of thermal expansion is neglected in the Boussinesq approximation. Numerical thermochemical models with compressibility and pressure-dependent thermal expansion have been conducted (e.g., Tackley, 1998; Hansen and Yuen, 2000), which show qualitatively similar results to our calculations; specifically, thermal plumes rising from thermochemical piles. As Anderson notes, the length scales of thermal instabilities tend to be larger in such models than in calculations with constant thermal expansion coefficients. But, for systems at least partially heated from below, decreased thermal expansion coefficient does not intrinsically preclude the development of plumes; the calculations yield fewer, larger plumes (Davies's commentary of 30 December on this problem is also quite relevant). The calculations that we report suggest that deep-mantle thermal instabilities will be geographically rooted near LLSVP margins. When it becomes viable to compute fully thermo- 
chemical spherical convection models with depth-dependent parameters, our expectation is that the configuration of upwellings will remain the same, only with larger-scale plume initiation at LLSVP margins. This prediction will need to be explored in the future. The destabilizing effects of post-perovskite phase transitions must also be considered, as such changes increase the potential for development of boundary layer instabilities, possibly countering any inhibiting effects of pressure dependence. However, at this time, the calculations have not been done, so speculation is appropriate for commentary, not for inclusion in a paper. We do note that some of the speculation in Anderson's comments of 25, 29, and 31 December appear at odds with the experience of actual numerical calculations, so his assertions about the dynamics are also premature.

Finally, realistic simulation of mantle circulation is a longterm research objective in geodynamics: all current models make some simplifying assumptions based on either computational considerations or lack of constraint on various thermodynamic parameters. There is often a resulting disconnect between practitioners who compute numerical models and geophysicists who speculate on plausible complexities not incorporated into those models. Similarly, there are large uncertainties in relating findings from different disciplines, as in our case of exploring interpretations of seismic observations by geodynamic models constrained by plate tectonic histories. Any claims of uniqueness would be laughable, but arguments by assertion without computational validation are of little merit as well.

\section{December 2006, Norman H. Sleep}

I comment on two of Anderson's points: (1) The thermal expansion coefficient in the deep mantle is so low that convection heated from below would be sluggish, and (2) any chemicaldensity stratification would overwhelm thermal expansion.

With regard to the thermal expansion coefficient, it useful to review the parameterized convection equation. The convective heatflow $q$ from a thin boundary layer is

$$
q=A k \Delta T\left[\frac{\rho g \alpha \Delta T}{\kappa \eta}\right]^{1 / 3}
$$

where $k$ is thermal conductivity, $\rho$ is density, $g$ is the acceleration of gravity, $\alpha$ is the thermal expansion coefficient, and $\kappa$ is the thermal diffusivity. The dimensionless multiplicative constant $A$ is on the order of 1 ; it depends on the boundary condition at the core-mantle boundary or the interface between "dregs" (chemically dense regions at the base of the mantle with no geometry or origin implied) and normal mantle. $\Delta T$ is the temperature contrast that actually drives convection and $\eta$ is the viscosity, which is a weighted average between the lowviscosity hot boundary layer and the conducting interior (Davai1le and Jaupart, 1993a,b, 1994; Solomatov, 1995; Solomatov and Moresi, 2000). The product $\rho \alpha$ rather than just $\alpha$ oc- curs in the equation, which partly offsets the effect of the decrease of thermal expansion with pressure. In addition, this product is raised to the $1 / 3$ power, making the heatflow insensitive to its value, provided it does not become zero or negative. To obtain the long-term thermal expansion coefficient, one needs to include the effect of multiphase systems, in which density depends on the partition of components among phases with temperature rather than on just the expansion of isochemical phases.

Anderson is correct that compositional variations can overwhelm thermal expansion. The Earth's core-mantle boundary and the rock-air interface are obvious extreme cases. The evolution of the lowermost mantle over time is relevant to plume convection heated from below. The core likely formed hot in the wake of the moon-forming impact. Conduction from the core thus has heated the lowermost mantle over geological time. In the absence of convection, the hot region at the base of the mantle would be quite thick, scaling to $\sqrt{\kappa t_{E}}$, where $t_{E}$ is the age of the Earth. The heatflow from the core would scale crudely with the square root of the age of the Earth. One needs to account for the cooling of the core over time to obtain a better conductive model.

Overall, chemical stratification in the lower mantle leads to predictable but complex behavior. Anderson's “dregs" layer is gradually stratified, so it does not convect internally. It is quite thick, so that a vigorous thermal boundary layer does not form above it. However, seismologists and petrologists have yet to constrain strongly the properties of conceivable chemically dense regions at the base of the mantle. We do not even know whether the dregs layer is thin (i.e., corresponding to the $\mathrm{D}^{\prime \prime}$ layer), or thick, as in a lava lamp. We do not know how dregs formed to begin with and whether current mantle processes enhance or disrupt stratification. Given this state of ignorance and physical complexity, observable manifestations of deep processes remain relevant. These manifestations include hotspot tracks and the possible detection of plumes by tomography.

\section{January 2007, Don L. Anderson}

The opposite of a vigorously convecting, well-stirred, highRayleigh-number homogeneous mantle-as usually modeledis a mantle stratified by intrinsic density. The possibility that the mantle is chemically stratified is usually dismissed outright, particularly by modelers. Compositional stratification is plausible and merits more attention (Anderson, this volume).

In his comment of 31 December, Sleep has added insight into this issue and the formation of "dregs" layers at chemical and viscosity boundaries. Much of the chemical layering was probably contemporaneous with accretion and Moon formation, but subsequent cooling can also create stratification, by the dregs mechanism (e.g., by light material leaving the core and newly dense basalt-eclogite in the proto-crust returning to the transition region). At some point in Earth's evolution, presumably as a result of cooling, the deep-subduction mode of plate tectonics kicked in; this mode returns surface material back to the mantle 
and displaces deeper mantle upward. But there are ways to form a chemically distinct $\mathrm{D}^{\prime \prime}$ layer without importing upper-crustal material from the surface.

Although the core-mantle boundary is the most obvious place (apart from the surface) to collect dregs from the mantle and dross from the core, it is not the only candidate boundary for collecting debris from Earth accretion and differentiation. As the mantle cools, the thick basaltic crust converts to eclogite, which sinks and collects at the 410- or 650-km discontinuity, depending on its temperature and major-element chemistry. Very cold $\mathrm{SiO}_{2}$-rich MORB eclogite may sink into the deeper mantle, until it reaches a density or viscosity barrier. Mantle viscosity may jump by two or three orders of magnitude at depths of $\sim 1000 \mathrm{~km}$ and $\sim 2000 \mathrm{~km}$ (Forte and Mitrovica, 2001). Big chunks of delaminate are not easily stirred back down to meterand centimeter-sized pieces. Olivine-rich cumulates and restites are buoyant and collect under the crust as a perisphere. The crust and proto-crust are the dross of terrestrial differentiation and the core is the dregs. These are just a few examples of possible chemical layers.

Plausible chemical differences among mantle lithologies give huge density differences compared to thermal expansion. Overall, chemical stratification in the mantle leads to complex behavior that is not necessarily predictable. The delamination scenario is particularly interesting. Delaminated blobs are fertile, fusible, and initially dense. They will form dregs in the mantle, where they become neutrally buoyant. They do not necessarily form a continuous dense layer. They then heat up and approach ambient mantle temperature, melt, and become buoyant. Their fates depend on their sizes. This scenario has not yet received numerical validation.

Sleep is correct in pointing out the need to generalize the expansion coefficient in a multiphase rock. One example is the gradual heating of garnet-majorite that may reside in the transition region as a result of the delamination of the lower part of the mafic crust of an overlying continent. The conversions of majorite back to garnet + pyroxene and then of garnet to magma give large density reductions. These effects, and compositional variations, can overwhelm thermal expansion.

The interpretation of tomography is more ambiguous than usually appreciated. Cold peridotite with $\mathrm{CO}_{2}$ (Presnall and Gudfinnsson, 2005, 2007) can be dense and yet have low seismic velocities. Eclogite has low shear-wave velocities compared to dry peridotite of the same density; dense sinkers of eclogite can have low shear-wave velocities and may be mistaken for hot rising plumes. Refractory peridotite has high seismic velocity but low density; in tomographic images it appears blue but is not sinking. Tomography is not a thermometer.

Sleep, however, is optimistic about the possible detection of plumes and the relationship of volcanic chains to $\mathrm{D}^{\prime \prime}$. In bottom-heated, but otherwise realistic, convection calculations, plumes, when they exist, are more like wandering strands of cooked spaghetti than rigid, upright rods, as often illustrated in

cartoons, or axisymmetric cylinders, as they appear when modeled in isolation from mantle flow. They would be invisible to tomography. However, plumes should spread out below the 650$\mathrm{km}$ discontinuity and the lithosphere and be detectable. But there is no seismic evidence for this (Deuss, this volume). If plumes exceed $\sim 1000 \mathrm{~km}$ in dimension they would overlap the normal scale of mantle convection and the broad upwellings that are intrinsic to an internally heated mantle in the absence of plumes.

\section{January 2007, Scott D. King}

Unwary readers should take warning that ordinary language undergoes modification to a high-pressure form when applied to the interior of the Earth. A few examples of equivalents follow:

\section{High Pressure Form \\ Certain \\ Undoubtedly \\ Positive proof \\ Unanswerable argument \\ Pure iron}

The discussion points by Anderson and Davies on the paper by Garnero et al. (this volume) remind me of the quote above from Birch (1952, p. 234). I refer readers to my own article in this volume, in which I present calculations that illustrate many of the effects mentioned in this discussion thread.

Let me begin with the rather obvious observation that the Earth is round. The surface area of the core-mantle boundary is approximately one-quarter of the surface, favoring a larger TBL at the base of the mantle than at the surface, all other things being equal. As Anderson reminds us, all things are not equal.

Anderson and Davies both appeal to temperature-dependent mantle rheology to support their views. Kellogg and King (1997), van Keken (1997), and Davies (1999) show that the large plume head, narrow tail structure is a natural consequence of convection heated from below with an Arrhenius form of rheology and otherwise uniform properties (e.g., Boussinesq convection). Few if any papers in the past decade have used a constant viscosity, so this objection begs the question. I demonstrate the effects of internal heating (uniform), pressure-dependent coefficient of thermal expansion (the major effect of compressible convection; c.f. Ita and King, 1994), upper-mantle phase transformations, and a deep stabilized layer at the base of the mantle (phase change or compositional) with a strong temperaturedependent viscosity, including an increase in viscosity with depth. These factors reduce the peak geoid, topographic, and heatflow anomalies, bringing the calculations closer to the observations, but produce deep plumes. It is worth noting that many other calculations have used temperature-dependent rheology with basal heating and in many cases internal heating and phase changes (e.g., Kiefer and Hager, 1992; Farnetani and Richards, 1994, 1995; Davies, 1995; Farnetani et al., 1996; Farnetani, 1997; Kellogg and King, 1997; King, 1997; van Keken, 1997; Leitch et al., 
1998; Leitch and Davies, 2001; Goes et al., 2004; Davies, 2005; Lin and van Keken, 2006a,b; Zhong, 2006), and it seems past time to put that objection to rest. A significant amount of work has been done.

Anderson reminds us that in a complex system, such as the mantle, it may be dangerous to make simplifying approximations that do not allow for a self-consistent formulation. However, his arguments beg the question as he proceeds to base his own arguments on at best the same inconsistent calculations or at worst simple theory that does not account for nonlinear feedback. As an example, any effect that decreases the lower-mantle Rayleigh number will cause the lower mantle to heat up, lowering the viscosity and increasing the flow. It is exactly because the mantle is a complex, self-organizing system, that such thought experiments, which do not consider feedback mechanisms, are every bit as dangerous (if not more so) as inconsistent calculations. A model as complex as reality is likely to yield very little understanding, because it will be as unwieldy as reality (e.g., Oreskes et al., 1994).

Although Anderson points out the effect of the increasing adiabatic temperature on viscosity, he does not mention the pressure-dependent effect (activation volume) that trades off with the adiabatic temperature and is not well constrained experimentally. Viscosity models of the Arrhenius form can be compared with other models of mantle viscosity (e.g., King and Masters, 1992). The argument presented by Anderson on the temperature effect of rheology has been used by many of us to explain the geoid and topography inversions for the past two decades and is consistent with what he often calls the standard model. This model has been included in many plume calculations, including most of the ones cited above, so it also begs the question. The lower mantle is made up of perovskite and ferropericlase, and most laboratory rheology measurements are made on olivine or olivine analogues. So self-consistency is in the eye of the beholder.

Ironically, the discussion has little to do with the observations in the original article of Garnero et al. Seismic observations at the base of the mantle are complex and not obviously consistent or inconsistent with any of the models in their original form. They are leading to interesting new ideas (e.g., Ishii and Tromp, 1999; Gurnis et al., 2000; Le Bars and Davaille, 2004; Schubert et al., 2004; Farnetani and Samuel, 2005) that one could envision being reconciled with Anderson's, Davies's, or a hybrid view of the mantle. As for Anderson's arguments regarding the modification of the plume theory, remember Kuhn's (1970) workscientific theories are always modified when presented with new observations. It seems to me that the proliferation of observations and ideas, including the chapter by Garnero et al. in this volume, show that the scientific process is working well.

\section{January 2007, Geoffrey F. Davies}

Anderson, in his 31 December comment, shifts from debating specifics to a general discussion of mantle dynamics. His repre- sentation of my views is inaccurate. I have never made such unqualified claims as "plumes must always exist, and they provide the only explanation for Hawaii, and the like." I therefore summarize here my actual views, for the record.

In my book (Davies, 1999) I argue that mantle convection can be usefully viewed as driven by two TBLs, with rather different dynamical styles, that interact to a substantial degree. Clearly plates from the top TBL are a major driving force, and clearly they affect plumes. Nevertheless some phenomena, Hawaii being the outstanding example, are quite well explained quantitatively by the thermal plume model, apparently with only secondary effects from the rest of the mantle system. That is why models of isolated plumes are a useful approximation to some aspects of the mantle system.

Sleep and I were among the first to conclude, from inferred plume fluxes, that the mantle is only secondarily heated from below, and therefore mainly heated by internal radioactivity (with some secular cooling). Indeed, for many years I have modeled the role of plates in the mantle system using only internal radioactive heating and excluding bottom heating and plumes. The point, of course, is to isolate those parts of the system that can be usefully isolated. It is therefore incorrect to claim that I do not account for radioactivity in the mantle on the basis of plume models tailored to isolate the plume phenomenon.

The mantle system clearly has complications, but that does not mean that parts of it cannot be usefully approximated by simpler models. Our understanding of the system has advanced considerably using this standard scientific approach.

Of course ultimately we would like to include all the main phenomena in one model. This is not yet possible, because models including both plates and plumes must be three dimensional, but 3-D models do not yet have the high resolution necessary for accurate modeling of plumes, although they are steadily approaching this goal.

Although Anderson refers to some recent models as being more realistic, it is important to appreciate that there are still important aspects that are not well understood or well constrained. This problem applies particularly to the top TBL, mainly because the rheology of the lithosphere is complicated and still not well characterized. Also, no model can accurately predict absolute mantle temperatures because of uncertainties in mantle rheology. Just because there is a relative progression of temperatures among some models does not provide a strong criterion for accepting or rejecting particular models.

Regarding alternatives to plumes, any model that involves a passive upper mantle responding to lithospheric changes would need to account for uplift preceding some flood basalt eruptions (e.g., Hooper et al., this volume, and references therein). Some other aspects of the mantle system, such as the role of plates in organizing mantle flow and the role of chemical heterogeneities (both as passive tracers and as active influences on buoyancy and melting), have long been discussed and modeled by practitioners. It has also long been appreciated that the mantle system is interconnected, self-organizing, self-regulating, far from equi- 
librium, and unsteady, and that thermodynamics and the role of the plates are important. I refer readers to my book (Davies, 1999) for a broad summary of the long history of work conducted by many people on these subjects.

The art of modeling the mantle system, as with any complicated system, is to construct models that are instructive, because they include important physics, while not depending strongly on parts that are poorly understood. This construction involves judgment and is therefore legitimately a matter of debate. There has always been active debate about plumes and alternatives to, or elaborations of, them. The useful role of this volume is to continue that traditional debate.

Scott King (his 2 January comment) points out in more detail than I did (30 December) that many models of plumes take account of things Anderson (31 December) claims have been disregarded. Anderson further claims (2 January) that "The possibility that the mantle is chemically stratified is usually dismissed outright, particularly by modelers." This assertion is incorrect and potentially misleading and damaging to forward progress. Possible compositional stratification, either in $\mathrm{D}^{\prime \prime}$ (Christensen and Hofmann, 1994) or in the lower third of the mantle (Kellogg et al., 1999), has been a major theme of debate and modeling in recent years. Possible present or past compositional differences between the upper and lower mantle have also emerged from recent modeling (e.g., Ogawa, 2003; Xie and Tackley, 2004; Davies, 2006). The rest of Anderson's comment is unquantified speculation.

\section{January 2007, Don L. Anderson}

There has been a tendency to regard plumes as a distinct, secondary mode of convection ... such a mode of flow has never been observed in any self-consistent numerical or laboratory experiment. (Larsen and Yuen, 1997, p. 1995)

King's comments are valid, but he and King and Redmond (this volume) are discussing and modeling normal mantle convection, albeit with enforced axisymmetry. Mantle plumes were invented as an alternate, or addition, to this broad-scale convection, which is driven by internal radioactivity, surface cooling, and plate tectonics. Calculations of mantle convection are indeed getting more realistic, but do they confirm the mantle plume hypothesis (i.e., an independent, narrow, plume mode of convection that is responsible for hotspots)?

The question of whether deep mantle upwellings can be independent, narrow, hot, and fast - as required in the mantle plume hypothesis - is at the core of more fundamental questions: Are the locations and dimensions of volcanic chains controlled by lithosphere and mantle heterogeneity, or by localized high absolute temperature and rapid upwelling? Do hotspots require a deep source of heat and material?

Larsen and Yuen (1997, p. 1995) addressed this problem:

The enigma of . . nearly stationary plumes ... in mantle convection arises in the hotspot hypothesis ... separation of time scales between the fast plume and adjacent mantle is necessary and, in fact, was invoked by Morgan in his original concept of plumes. . . . plume studies have usually modeled a plume in isolation from the rest of the mantle. ... Upwelling plumes always occur as part of the main convecting system (rather than independently). In particular, there is a problem of obtaining hotspot-like plumes, which must satisfy the requirements of being fast as compared to the ambient mantle circulation and fairly thin.... Mantle plumes have peak ascending velocities of 20 meters/yr.

What distinguishes mantle plumes, as conventionally defined - and as widely perceived outside of the geodynamics/convection community - from normal convection upwellings is higher temperatures, higher ascent velocities, and much smaller dimensions. Initially, mantle plumes were also thought to be stationary. Mantle plumes differ from alternative mechanisms in being entirely thermal in nature and in having a source deep in the mantle (although this idea is continually being modified in the face of observation, e.g., Courtillot et al., 2003). Starting plumes differ in uplift history from alternative mechanisms. It is these characteristics that stimulated the question "Do mantle plumes exist?" In this debate, no one is challenging the existence of convection, broad upwellings, or small-scale features that can be attributed to extension and fertile blob scales. Kuhn (1970) noted this tendency to talk past one another when a paradigm is challenged.

My comments were specifically addressed only to those studies that isolate the lower TBL from the rest of the system, or that argue for narrow plumes or neglect such effects as feedback: "these [effects] are ignored in all calculations that yield narrow whole-mantle plumes. None of the fluid dynamic calculations used ... to support their view take [these] into account ... [more realistic calculations] do not predict plume-like dimensions and timescales at D" depths" (my comment of 25 December in this discussion thread; emphasis is new).

I do not suggest that all studies have ignored pressure, layering, or internal heating. I referred to studies that allowed selforganization and did not support the widely held narrow-plume assumption. These studies, however, do not address the smallscale and other characteristics of hotspots and volcanic chains that motivated the plume hypothesis.

Recent fluid dynamic simulations (Zhong, 2006; King and Redmond, this volume) and most of the above comments and references refer to normal mantle convection or superplumes, not to the original mantle plume hypothesis. Broad plumes are not what Sleep, Larsen, Yuen, and Olsen, for example, are modeling. Serious attempts have been made to rescue the original narrowplume hypothesis (Larsen and Yuen, 1997), but these models violate other constraints. Although many workers have abandoned the small-scale stationary plume idea, many others attribute the difficulty in observing plumes to their very small size.

Although there are exceptions, most models assume wholemantle convection. The more interesting calculations allow for chemical stratification (e.g., Tackley and Xie, 2002). Quite often, scaling between shear velocity and density is assumed, instead of an appropriate thermodynamic scaling via volume 
(Birch, 1952). In seismology, low shear velocity is still usually attributed to high temperature and low density.

There are various mechanisms for causing uplift before and concurrent with volcanism (e.g., delamination). The plume hypothesis is unique in requiring major uplift many millions of years before the eruptions. Models that involve fertile blobs do not require such precursory uplift.

Birch (1952) developed the machinery for self-consistent treatments of mantle dynamics. Kuhn (1970) did argue that scientific theories can be modified, but as a prelude to his discussion of why the concepts of Ptolemy, aether, and phlogiston failed; those concepts became so contrived and amended, and had so many versions, that people lost interest. The existence of a chemically layered mantle with large, dense thermochemical features (piles) at the base is not being disputed; in fact it was predicted. It is the association of these with surface volcanism that might be regarded as unquantified speculation. The shallow mantle and the transition region also have suggestive correlations with tectonics. It is interesting that the plume hypothesismotivated by the idea of a buoyant hot D"-now requires importation of cold dense downwellings from the surface. The latter may occur, but it does make the plume hypothesis immune to new observations and theory.

\section{January 2007, Alexei Ivanov}

Davies (his comment of 3 January) writes "Regarding alternatives to plumes, any model that involves a passive upper mantle responding to lithospheric changes would need to account for uplift preceding some flood basalt eruptions (e.g., Hooper et al., this volume, and references therein)." The Siberian Traps were not preceded by uplift (e.g., Ivanov, this volume, and references therein).

Davies refers to uplift preceding some flood basalts but neglects the absence of uplift preceding others. The Siberian Traps and Columbia River flood basalts are $4 \times 10^{6} \mathrm{~km}^{3}$ and $0.2 \times 10^{6}$ $\mathrm{km}^{3}$ in volume, respectively. Which example would seem more important to the debate regarding plumes and alternatives?

There is a mathematical rule that in a complex system, evidence can always be found in support of a hypothesis. Probably we all take advantage of this.

\section{January 2007, Geoffrey F. Davies}

Anderson's latest comment (5 January) reiterates his opinion but adds little to the continuing debate. However it does illustrate the current level of debate and disagreement among modelers, which is sufficiently diverse to allow Anderson to choose studies that support his contentions. This diversity is just the current manifestation of a debate that has always been vigorous, despite charges to the contrary.

The debates about plumes and the accumulation of new observations have led many to consider variations on Morgan's initial proposals. For example, in my opinion there was never a good rationale, or need, for plumes to be rigorously fixed, rather than simply slow-moving (see Davies, 2005). However this process of learning and modifying has been portrayed by some as rendering plumes arbitrarily adaptable and therefore untestable and unscientific. There have certainly been many poorly motivated proposals invoking plumes, which I would join in criticizing, but there has been a core of quantitative work that makes quantitative predictions. A summary of some significant predictions and relevant observations has recently been given by Campbell and Davies (2006).

An irony here is that two charges that have been madelack of consideration of alternatives and arbitrarily malleable hypotheses-are mutually contradictory. They cannot both be true. Science never ties up every last loose end of observation, especially in studies of very complicated subjects, such as Earth. Thus there is always some level of uncertainty to nourish dissenters. Ultimately it is a matter of judgment as to when to consider the issue decided and move on, though all conclusions are conditional and subject to later modification or replacement.

\section{January 2007, Ed J. Garnero, Thorne Lay, and Allen McNamara}

Debate about the nature of hotspot volcanism intrinsically raises the question of what the large-scale configuration of mantle convection is. As perhaps the foremost problem in global geophysics, it comes as no surprise that strongly held and conflicting perspectives of this issue persist despite extensive recent advances of our understanding of Earth's internal structure and processes. Enthusiasm ebbs and flows for end-member scenarios of whole-mantle or layered-mantle convection, and there is, as yet, no consensus other than agreement that the most likely scenario involves a more complex thermochemical system than either end-member. We think it is fair to state that many deepEarth geophysicists find the evidence favoring large-scale mixing of the mantle more compelling than evidence for strongly layered convection, but probably the strongest statement we would defend is that no line of evidence yet precludes significant flow between the upper and lower mantles.

Given that perspective, our chapter highlights some of the exciting deep-mantle high-resolution seismic findings in the context of state-of-the-art numerical geodynamical calculations that do allow upper-mantle flow to influence the deep mantle. Simply put, we addressed this question: if plumes originate from the deep mantle, what are their possible geographic systematics, given the recent seismic and geodynamic analyses? The extensive debate spawned by our article raised several important factors, most of which were beyond the article's intended scope, but all of which bear on the fundamental question of what the configuration of the mantle dynamic system is.

Our article highlighted 3-D spherical numerical calculations of McNamara and Zhong (2005), which explore thermo- 
chemical dynamics. These calculations assumed an initially dense, chemically distinct layer in the lowermost several hundred kilometers of the mantle, adopted the Boussinesq approximation, incorporated temperature-dependent viscosity, and used a roughly equal ratio of basal to internal heating. The past 119 Ma of plate motions from Lithgow-Bertelloni and Richards (1998) were imposed as a surface flow boundary condition such that upper-mantle downwellings spatially control the deepmantle flow that interacts with the chemically stratified layer. The hot, dense material of that layer is swept into large piles under upwelling return flow, yielding a configuration of large piles of chemically distinct material that have strong spatial affinity to LLSVPs in the deep mantle observed by seismology.

Our intention was not to predict plumes or deep-mantle plume-hotspot connections, but the computations yield boundary layer instabilities on the edges of the chemical piles that rise as plumes in the 3-D flow (admittedly, the detailed character of the instabilities is not fully resolved and does depend on the Boussinesq approximation, although the physics of compressibility will likely not change the results in general). The simulations show that the dense-pile material influences the plume distribution. This configuration is in general agreement with the empirically observed tendency for hotspot volcanism to overlay lateral margins of deep-mantle, low-velocity provinces (Thorne et al., 2004). Thus, plumes are a consequence of our calculations, not an input design. There is no injection of material at the base of the model, both internal and bottom heating are present, and unlike most earlier models, we explicitly incorporated initial chemical stratification in the system. The present discussion thread should not confuse the readers about what is actually in our article. Even if the descent of slab material is more inhibited or limited than in the calculations, the general flow pattern and implications for where plume instabilities might arise is unlikely to change.

The take-home message is that the presence of dense thermochemical piles in the deep mantle can influence the location of boundary layer upwellings, providing a geometric distribution of boundary layer instabilities that is absent in mantle flow models without piles. Thus, although vertical continuity of flow to the surface is not directly constrained, it is attractive to consider the possible connection between upwellings on pile margins (whether these involve continuous plume conduits or fragmented plumes or blobs) and hotspots at Earth's surface. Passive rifting at ridges may cause separate, relatively shallow upwellings that have no direct connection to lower boundary layer instabilities, so we focus on the possible linkage to hotspots. The hotspot research community may find it valuable to keep an eye on developments in deep-mantle research as the plume debate progresses.

\section{REFERENCES}

Anderson, D.L., 1989, Theory of the Earth: Boston, Blackwell Scientific, 366 p. http://caltechbook.library.caltech.edu/14/.
Anderson, D.L., 2007 (this volume), The Eclogite engine: Chemical geodynamics as a Galileo thermometer, in Foulger, G.R., and Jurdy, D.M., Plates, plumes, and planetary processes: Boulder, Colorado, Geological Society of America Special Paper 430, doi: 10.1130/2007.2430(03).

Beutel, E., and Anderson, D.L., 2007 (this volume), Ridge-crossing seamount chains: A nonthermal approach, in Foulger, G.R., and Jurdy, D.M., Plates, plumes, and planetary processes: Boulder, Colorado, Geological Society of America Special Paper 430, doi: 10.1130/2007.2430(19).

Birch, A.F., 1952, Elasticity and constitution of the Earth's interior: Journal of Geophysical Research, v. 57, p. 227-286.

Campbell, I.H., and Davies, G.F., 2006, Do mantle plumes exist?: Episodes, v. 29 , p. $162-168$.

Christensen, U.R., and Hofmann, A.W., 1994, Segregation of subducted oceanic crust in the convecting mantle: Journal of Geophysical Research, v. 99, p. 19,867-19,884.

Courtillot, V., Davaille, A., Baesse, J., and Stock, J., 2003, Three distinct types of hotspots in the Earth's mantle: Earth and Planetary Science Letters, v. 205, p. 295-308.

Davaille A., and Jaupart, C., 1993a, Thermal convection in lava lakes: Geophysical Research Letters, v. 20, p. 1827-1830.

Davaille A., and Jaupart, C., 1993b, Transient high-Rayleigh-number thermal convection with large viscosity variations: Journal of Fluid Mechanics, v. 253 , p. $141-166$.

Davaille A., and Jaupart, C., 1994, The onset of thermal convection in fluids with temperature-dependent viscosity: Application to the oceanic mantle: Journal of Geophysical Research, v. 99, p. 19,853-19,866.

Davies, G.F., 1995, Penetration of plates and plumes though the mantle transition zone: Earth and Planetary Science Letters, v. 133, p. 507-516.

Davies, G.F., 1999, Dynamic Earth: Plates, plumes and mantle convection: Cambridge, Cambridge University Press, $460 \mathrm{p}$.

Davies, G.F., 2005, A case for mantle plumes: Chinese Science Bulletin, v. 50, p. 1541-1554. http://www.mantleplumes.org/WebDocuments/ChineseSci Bull3papers2005.pdf.

Davies, G.F., 2006, Gravitational depletion of the early Earth's upper mantle and the viability of early plate tectonics: Earth and Planetary Science Letters, v. 243 , p. $376-382$.

Deuss, A., 2007 (this volume), Seismic observations of transition-zone discontinuities beneath hotspot locations, in Foulger, G.R., and Jurdy, D.M., Plates, plumes, and planetary processes: Boulder, Colorado, Geological Society of America Special Paper 430, doi: 10.1130/2007 .2430(07).

Farnetani, C.G., 1997, Excess temperature of mantle plumes; The role of chemical stratification across D": Geophysical Research Letters, v. 24, p. 1583 1586.

Farnetani, C.G., and Richards, M.A., 1994, Numerical investigations of the mantle plume initiation model for flood basalt events: Journal of Geophysical Research, v. 99, p. 13,813-13,833.

Farnetani, C.G., and Richards, M.A., 1995, Thermal entrainment and melting in mantle plumes: Earth and Planetary Science Letters. v. 136, p. 251267.

Farnetani, C.G., and Samuel, H., 2005, Beyond the thermal plume paradigm: Geophysical Research Letters, v. 32, art. no. L07311, doi: 10.1029/2005 GL022360.

Farnetani, C.G., Richards, M.A., and Ghiorso, M.S., 1996, Petrological models of magma evolution and deep crustal structure beneath hotspots and flood basalt provinces: Earth and Planetary Science Letters, v. 143, p. 81-94.

Forte, A.M., and Mitrovica, J.X., 2001, Deep-mantle high-viscosity flow and thermochemical structure inferred from seismic and geodynamic data: Nature, v. 410, p. 1049-1056, doi: 10.1038/35074000.

Garnero, E.J., Lay, T., and McNamara, A., 2007 (this volume), Implications of lower-mantle structural heterogeneity for existence and nature of wholemantle plumes, in Foulger, G.R., and Jurdy, D.M., Plates, plumes, and plan- 
etary processes: Boulder, Colorado, Geological Society of America Special Paper 430, doi: 10.1130/2007.2430(05).

Goes, S., Cammarano, F., and Hansen, U., 2004, Synthetic seismic signature of thermal mantle plumes: Earth and Planetary Science Letters, v. 218, p. 403-419.

Griffiths, R.W., and Campbell, I.H., 1990, Stirring and structure in mantle plumes, Earth and Planetary Science Letters, v. 99, p. 66-78.

Grigné, C., Labrosse, S., and Tackley, P.J., 2005, Convective heat transfer as a function of wavelength: Implications for the cooling of the Earth: Journal of Geophysical Research, v. 110, art. no. B03409, doi: 10.1029/2004 JB003376.

Gurnis, M., Mitrovica, J.X., Ritsema, J., van Heijst, H. J., 2000, Constraining mantle density structure using geological evidence of surface uplift rates; The case of the African superplume: Geochemistry, Geophysics, Geosystems, v. 1, art. no. 1999G000035.

Hansen, U., and Yuen, D.A., 2000, Extended-Boussinesq thermal-chemical convection with moving heat sources and variable viscosity: Earth and Planetary Science Letters, v. 176, p. 401-411.

Hooper, P.R., Camp, V., Reidel, S., and Ross, M., 2007 (this volume), The origin of the Columbia River flood basalt province: Plume versus nonplume models, in Foulger, G.R., and Jurdy, D.M., Plates, plumes, and planetary processes: Boulder, Colorado, Geological Society of America Special Paper 430, doi: 10.1130/2007.2430(30).

Ishii, M., and Tromp, J., 1999, Normal-model and free-air gravity constraints on lateral variations in velocity and density of the earth's mantle: Science, v. 285 , p. $1231-1236$.

Ita, J.J., and King, S.D., 1994, The sensitivity of convection with an endothermic phase change to the form of governing equations, initial conditions, aspect ratio, and equation of state: Journal of Geophysical Research, v. 99, p. $15,919-15,938$.

Ivanov, A., 2007 (this volume), Evaluation of different models for the origin of the Siberian Traps, in Foulger, G.R., and Jurdy, D.M., Plates, plumes, and planetary processes: Boulder, Colorado, Geological Society of America Special Paper 430, doi: 10.1130/2007.2430(31).

Kaula, W.M., 1983, Minimal upper mantle temperature variations consistent with observed heat flow and plate velocities: Journal of Geophysical Research, v. 88 , p. 10,323-10,332.

Kellogg, L.H., and King, S.D., 1997, The effect of temperature dependent viscosity on the structure of new plumes in the mantle: Results of a finite element model in a spherical, axisymmetric shell: Earth and Planetary Science Letters, v. 148, p. 13-26.

Kellogg, L.H., Hager, B.H., and van der Hilst, R.D., 1999, Compositional stratification in the deep mantle: Science, v. 283, p. 1881-1884.

Kiefer, W.H., and Hager, B.H., 1992, Geoid anomalies and dynamic topography from convection in cylindrical geometry: Applications to mantle plumes on Earth and Venus: Geophysical Journal International, v. 108, p. $198-214$

King, S.D., 1997, Geoid and topographic swells over temperature-dependent thermal plumes in spherical-axisymmetric geometry: Geophysical Research Letters, v. 24, p. 3093-3096.

King, S.D., and Masters, G., 1992, An inversion for radial viscosity structure using seismic tomography: Geophysical Research Letters, v. 19, p. 15511554 .

King, S.D., and Redmond, H.L., 2007 (this volume), The structure of thermal plumes and geophysical observations, in Foulger, G.R., and Jurdy, D.M., Plates, plumes, and planetary processes: Boulder, Colorado, Geological Society of America Special Paper 430, doi: 10.1130/2007.2430(06).

Kuhn, T.S., 1970, The structure of scientific revolutions (2nd edition): Chicago, University of Chicago Press, 206 p.

Larsen, T.B., and Yuen, D.A., 1997, Ultrafast upwelling bursting through the upper mantle: Earth and Planetary Science Letters, v. 146, p. 393-400.

Le Bars, M., and Davaille, A., 2004, Whole layer convection in a heterogeneous planetary mantle: Journal of Geophysical Research, v.109, art. no. B03403.
Leitch, A.M., and Davies, G.F., 2001, Mantle plumes and flood basalts: Enhanced melting from plume ascent and an eclogite component: Journal of Geophysical Research, v. 106, p. 2047-2059.

Leitch, A.M., Davies, G.F., and Wells, M., 1998, A plume head melting under a rifted margin: Earth and Planetary Science Letters, v. 161, p. 161-177.

Lenardic, A., and Kaula, W.M., 1994, Tectonic plates, D" thermal structure, and the nature of mantle plumes: Journal of Geophysical Research, v. 99, art. no. 94JB00466, p. 15,697-15,708.

Lin, S.-C., and van Keken, P.E., 2006a, Dynamics of thermochemical plumes: 1. Plume formation and entrainment of a dense layer: Geochemistry, Geophysics, Geosystems, v. 7, art. no. Q02006.

Lin, S.-C., and van Keken, P.E., 2006b, Dynamics of thermochemical plumes: 2. Complexity of plume structures and its implications for mapping mantle plumes: Geochemistry, Geophysics Geosystems, v. 7, Q02006.

Lithgow-Bertelloni, C., and Richards, M.A., 1998, The dynamics of Cenozoic and Mesozoic plate motions: Reviews of Geophysics, v. 36, p. 27-78.

Lowman, J., King, S., and Gable, C., 2001, The influence of tectonic plates on mantle convection patterns, temperature and heat flow: Geophysical Journal International, v. 146, p. 619, doi:10.1046/j.1365-246X.2001 .00471 .

McNamara, A.K., and Zhong, S., 2005, Thermochemical piles under Africa and the Pacific: Nature, v. 437, p. 1136-1139.

Mitrovica, J.X., 1996, Haskell (1935) revisited: Journal of Geophysical Research, v. 101 , p. 555-569.

Nakagawa, T., and Tackley, P.J., 2006, Three-dimensional structures and dynamics in the deep mantle: Effects of post-perovskite phase change and deep mantle layering: Geophysical Research Letters, v. 33, art. no. L12S11, doi: 10.1029/2006GL025719.

Nataf, H-C., 1991, Mantle convection, plates, and hotspots; Tectonophysics, v. 187, p. $361-371$

Ogawa, M., 2003, Chemical stratification in a two-dimensional convecting mantle with magmatism and moving plates: Journal of Geophysical Research, v. 108 , p. 2561

Oreskes, N., Shrader-Frechette, K., and Belitz, K., 1994, Verification, validation, and confirmation of numerical models in the Earth sciences: Science, v. 263, p. 641-646.

Parmentier, E.M., C. Sotin, and B.J. Travis, 1994, Turbulent 3-D thermal convection in an infinite Prandtl number, volumetrically heated fluidImplications for mantle dynamics: Geophysical Journal International, v. 116, p. 241-251.

Phillips, B.R., and Bunge, H.-P., 2005, Heterogeneity and time dependence in 3D spherical mantle convection models with continental drift: Earth and Planetary Science Letters, v. 233, p. 121-135.

Presnall, D.C., and Gudfinnsson, G.H., 2005, Carbonate-rich melts in the oceanic low-velocity zone and deep mantle, in Foulger, G.R., et al., eds., Plates, plumes, and paradigms: Boulder, Colorado, Geological Society of America Special Paper 388, p. 207-216, doi: 10.1130/2005.2388(13)

Presnall, D.C., and Gudfinnsson, G., 2007, Global Na8-Fe8 Systematics of MORBs: Implications for mantle heterogeneity, temperature, and plumes, abstract EGU2007-A-00436, European Geophysical Union General Assembly, 15-20 April, Vienna.

Samuel, H., and Farnetani, C.G., 2003, Thermochemical convection and helium concentrations in mantle plumes: Earth and Planetary Science Letters, v. 207 , p. $39-56$.

Schubert, G., Masters, G., Olson, P., and Tackley, P., 2004, Superplumes or plume clusters?: Physics of Earth and Planetary Interiors, v. 146, p. 147-162.

Sleep, N.H., 2007 (this volume), Origins of the plume hypothesis and some of its implications, in Foulger, G.R., and Jurdy, D.M., Plates, plumes, and planetary processes: Boulder, Colorado, Geological Society of America Special Paper 430, doi: 10.1130/2007.2430(02).

Solomatov, V.S., 1995, Scaling of temperature- and stress-dependent viscosity convection: Physics of Fluids, v. 7, p. 266-274.

Solomatov, V.S., and Moresi, L.-N., 2000, Scaling of time-dependent stagnant lid convection: Application to small-scale convection on Earth and other 
terrestrial planets: Journal of Geophysical Research, v. 105, p. 21,79521,817 .

Tackley, P.J., 1998, Three-dimensional simulations of mantle convection with a thermal-chemical boundary layer D", in Gurnis, M., et al., eds., The coremantle boundary region: Washington, D.C., American Geophysical Union Geodynamics Monograph 28, p. 231-253.

Tackley, P.J., 2002, Strong heterogeneity caused by deep mantle layering: Geochemistry, Geophysics, Geosystems, v. 3, doi: 10.1029/2001GC000167.

Tackley, P.J., and Xie, S., 2002, The thermo-chemical structure and evolution of Earth's mantle: constraints and numerical models: Philosophical Transactions of the Royal Society of London A, v. 360, p. 2593-2609.

Thorne, M., Garnero, E.J., and Grand, S., 2004, Geographic correlation between hot spots and deep mantle lateral shear- wave velocity gradients: Physics of the Earth and Planetary Interiors, v. 146, p. 47-63.

Tozer, D.C., 1973, Thermal plumes in the Earth's mantle: Nature, v. 244, p. 398 400.

Van Keken, P.E., 1997, On entrainment in starting mantle plumes: Earth and Planetary Science Letters, v. 148, p. 1-12.

Xie, S., and Tackley, P.J., 2004, Evolution of U-Pb and Sm-Nd systems in numerical models of mantle convection and plate tectonics: Journal of Geophysical Research, v. 109, doi: 10.1029/2004JB003176.

Zhong, S., 2006, Constraints on thermochemical convection of the mantle from plume heat flux, plume excess temperature, and upper mantle temperature: Journal of Geophysical Research, v. 111, art. no. B04409.

[AQ1] Any update yet? If the article is not yet accepted, it should be deleted here and changed to a "personal communication" citation in the text.

[AQ2] Any update yet? If the article is not yet accepted, it should be deleted here and changed to a "personal communication" citation in the text.

[AQ3] Is this quote from Garnero et al. (this volume)?

[AQ4] Please add this reference to the reference list. Or do you mean Leitch and Davies 1991?

[AQ5] Please specify where this equation comes from: the Anderson chapter in this volume, or? 
